$\mathcal{E}_{\text {International }}^{\text {Insport Forum }}$

\title{
Is Congestion Pricing Fair?
}

Consumer and Citizen Perspectives on Equity Effects

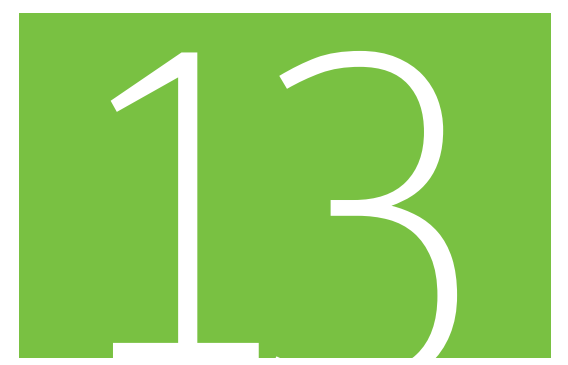

Discussion Paper 2016 • 13

Jonas Eliasson

Department for Transport Science,

KTH Royal Institute of Technology

Stockholm, Sweden 


\title{
E International Transport Forum
}

\section{Is congestion pricing fair? \\ Consumer and citizen perspectives on equity effects}

Discussion Paper No. 2016-13

\author{
Prepared for the Roundtable on \\ Income inequality, social inclusion and mobility
}

(4-5 April 2016; Paris, France)

\begin{abstract}
Jonas Eliasson
Department for Transport Science, KTH Royal Institute of Technology

Stockholm, Sweden
\end{abstract}

April 2016 


\title{
The International Transport Forum
}

The International Transport Forum is an intergovernmental organisation with 57 member countries. It acts as a think tank for transport policy and organises the Annual Summit of transport ministers. ITF is the only global body that covers all transport modes. The ITF is politically autonomous and administratively integrated with the OECD.

The ITF works for transport policies that improve peoples' lives. Our mission is to foster a deeper understanding of the role of transport in economic growth, environmental sustainability and social inclusion and to raise the public profile of transport policy.

The ITF organises global dialogue for better transport. We act as a platform for discussion and pre-negotiation of policy issues across all transport modes. We analyse trends, share knowledge and promote exchange among transport decision-makers and civil society. The ITF's Annual Summit is the world's largest gathering of transport ministers and the leading global platform for dialogue on transport policy.

The Members of the Forum are: Albania, Armenia, Argentina, Australia, Austria, Azerbaijan, Belarus, Belgium, Bosnia and Herzegovina, Bulgaria, Canada, Chile, China (People's Republic of), Croatia, Czech Republic, Denmark, Estonia, Finland, France, Former Yugoslav Republic of Macedonia, Georgia, Germany, Greece, Hungary, Iceland, India, Ireland, Israel, Italy, Japan, Korea, Latvia, Liechtenstein, Lithuania, Luxembourg, Malta, Mexico, Republic of Moldova, Montenegro, Morocco, the Netherlands, New Zealand, Norway, Poland, Portugal, Romania, Russian Federation, Serbia, Slovak Republic, Slovenia, Spain, Sweden, Switzerland, Turkey, Ukraine, the United Kingdom and the United States.

\author{
International Transport Forum \\ 2 rue André Pascal \\ F-75775 Paris Cedex 16 \\ contact@itf-oecd.org \\ www.itf-oecd.org
}

\section{ITF Discussion Papers}

ITF Discussion Papers make economic research, commissioned or carried out in-house at ITF, available to researchers and practitioners. They describe preliminary results or research in progress by the author(s) and are published to stimulate discussion on a broad range of issues on which the ITF works. Any findings, interpretations and conclusions expressed herein are those of the authors and do not necessarily reflect the views of the International Transport Forum or the OECD. Neither the OECD, ITF nor the authors guarantee the accuracy of any data or other information contained in this publication and accept no responsibility whatsoever for any consequence of their use. This document and any map included herein are without prejudice to the status of or sovereignty over any territory, to the delimitation of international frontiers and boundaries and to the name of any territory, city or area. Comments on Discussion Papers are welcome. 


\section{Acknowledgements}

The data used in this study used comes from a survey developed and carried out in Stockholm, Lyon and Helsinki by Carl Hamilton, Jonas Eliasson, Karin Brundell-Freij, Kati Kiskilää, Charles Raux, Stephanie Souche and Juha Tervonen, funded by the ERA-NET programme SURPRICE. The Gothenburg data collection was carried out by Maria Börjesson, Jonas Eliasson and Carl Hamilton. 


\begin{abstract}
This paper discusses and analyses whether congestion charges can be considered to be "fair" in different senses to the word. Two different perspectives are distinguished: the consumer perspective and the citizen perspective. The consumer perspective is the traditional one in equity analyses, and includes changes in travel costs, travel times and so on. Using data from four European cities, the analysis shows that high-income groups pay more than low-income groups, but low-income groups pay a higher share of their income. This paper argues that which distributional measure is most appropriate depends on the purpose(s) of the charging system. The citizen perspective is about individuals' view of social issues such as equity, procedural fairness and environmental issues. This paper argues that an individual can be viewed as a "winner" from a citizen perspective if a reform (such as congestion pricing) is aligned with her views of what is socially desirable. Using the same data set, this paper analyses to what extent different income groups "win" or "lose" from a citizen perspective -i.e., to what extent congestion pricing is aligned with the societal preferences of highand low-income groups.
\end{abstract}




\section{Table of Contents}

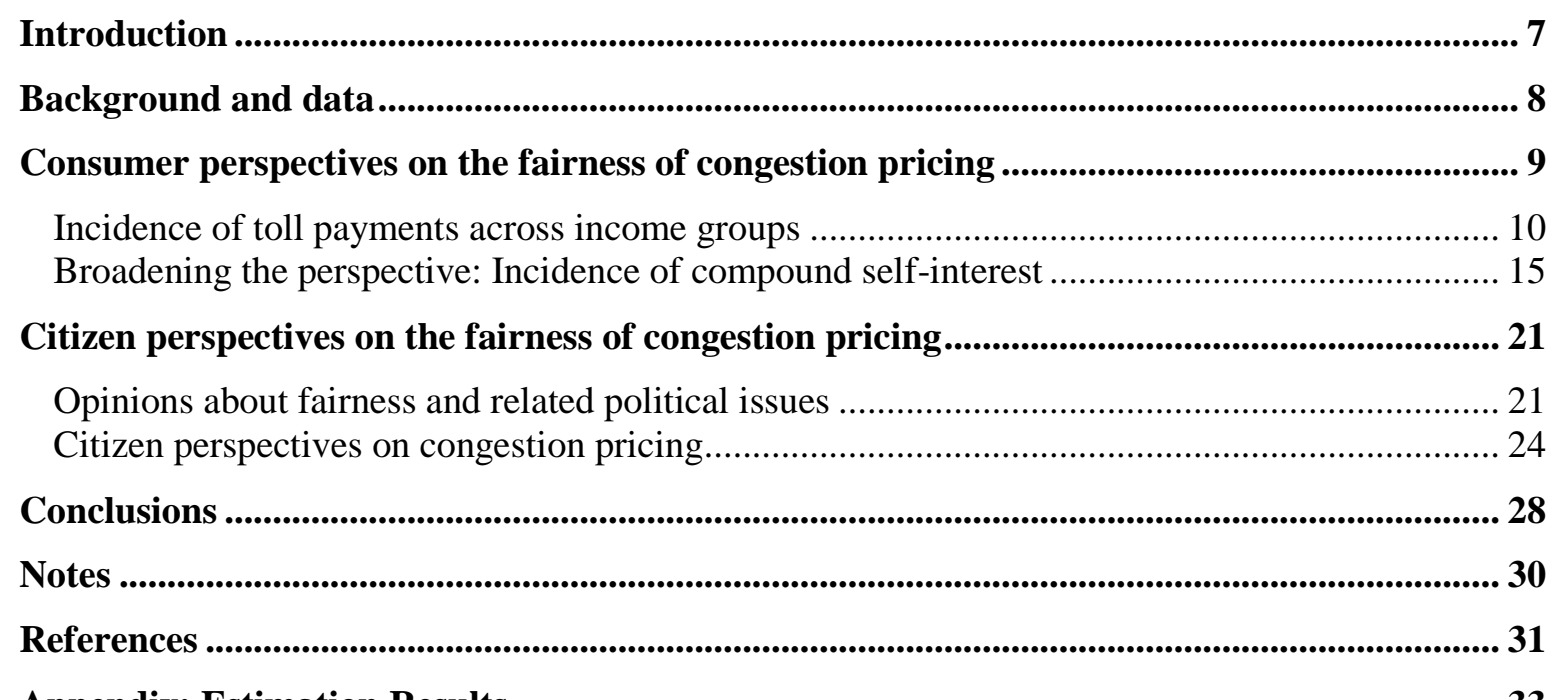

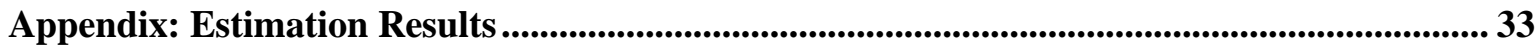

\section{Figures}

Figure 1. Share of population who pay various amounts in tolls. .................................................. 10

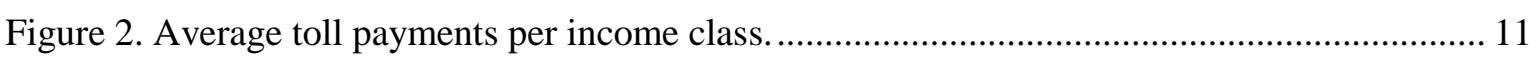

Figure 3. Average toll payments as share of income, per income class......................................... 11

Figure 4. Average toll payments per income group, with company car exemption (black) and

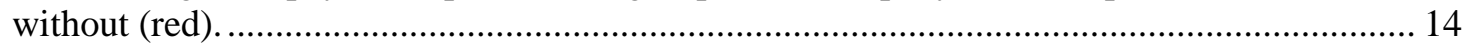

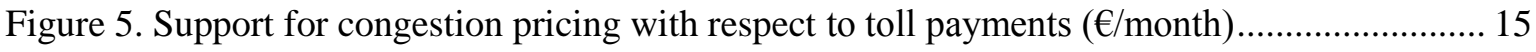

Figure 6. Support for congestion pricing in different income groups, split by those who pay little or nothing (black) and those who pay moderate or large amounts (blue)........................ 17

Figure 7. Average compound self-interest per income group, relative to the mean in each city ..... 20

Figure 8. Support for congestion charges across income groups in different cities (two different

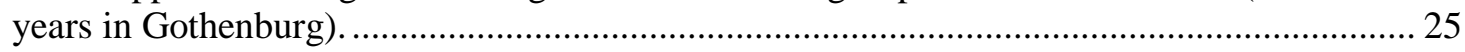

Figure 9. Consumer and citizen components of the "utility" of congestion pricing, separated by

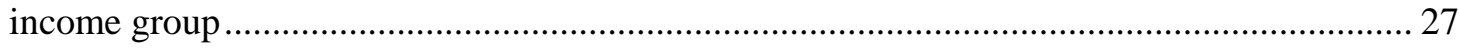

Figure 10. Consumer and citizen components of the "utility" of congestion pricing, with "citizen utility" separated into its subcomponents, and separated by income group ..... 28 
Jonas Eliasson - Is congestion pricing fair?

\section{Tables}

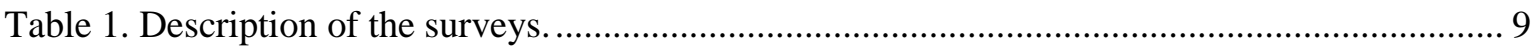

Table 2. Suits index (overall regressivity/progressivity) of the congestion charges ........................ 12

Table 3. Share of each income class who would pay more than $40 € /$ month in congestion charges 13

Table 4. Estimation results: impact of self-interest variables on attitude to congestion pricing. ..... 18

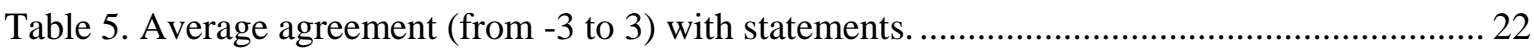

Table 6. Correlation between income and agreement with the statement. ..................................... 23

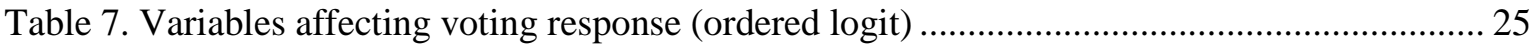




\section{Introduction}

Most transport economists and urban planners would agree that scarce road capacity should be priced, and would hence support congestion pricing as a way to decrease traffic jams and use scarce urban land more efficiently. There is also substantial evidence from several cities that congestion pricing indeed works as intended, and that the aggregate social benefits can by far exceed investment and operating costs, provided that the system is well designed.

However, perhaps the most pervasive argument against congestion pricing is that it is unfair - a statement that can be interpreted in several different ways. The purpose of this paper is to discuss and analyse to what extent congestion pricing is "fair", in several different senses of the word. The quantitative analyses use survey data from four European cities: Stockholm and Gothenburg (Sweden), Helsinki (Finland) and Lyon (France). Stockholm and Gothenburg have operational congestion charging systems, whereas Helsinki and Lyon do not. In the survey, respondents answered a range of questions regarding their travel behaviour, their views of fairness and several societal/political questions, and how they would vote in a hypothetical referendum about congestion pricing.

The purpose is to explore the fairness of congestion pricing from two perspectives, which can be called the consumer and citizen perspectives ${ }^{1}$ (Nyborg, 2000; Sagoff, 1988). The consumer perspective includes how an individual is affected personally: how much tolls she pays, how much travel time she saves, her valuation of travel time and (if specified) the benefit of the recycled revenues. The citizen perspective is about what the individual sees as "fair", "just" or "desirable" from a social perspective, disregarding her own self-interest. Clearly, these two perspectives are affected by each other. What an individual thinks is "fair" is often correlated with what will benefit herself - after all, (all) humans are not saints, at least not on the subconscious level. But just as clearly, opinions about societal issues are not only determined by self-interest. There is abundant evidence that people's votes and behaviour are also affected by other concerns than self-interest, for example concerns about equity, environment and procedural fairness.

Hence, congestion pricing may be seen as "unfair" in two senses, or both. First, they may be seen as unfair in a "consumer" perspective, if they hurt low income groups disproportionately: if the poor pay more in tolls than the rich, if they value their times savings less, or if they get less benefit from the revenues. Effects can either be measured in absolute terms or proportional to income; I will argue that which is the most appropriate measure depends on to what extent the charges are (also) a fiscal policy. The consumer perspective - tolls paid, time gained and revenue recycling - is the traditional perspective on fairness in equity analyses of congestion charges, and there is an abundant literature (e.g. Eliasson \& Mattsson, 2006; Karlström \& Franklin, 2009; Levinson, 2010; Small, 1992). This perspective is analysed and discussed in the first part of the paper (section 3). Comparing results from the four cities show some striking similarities, despite different system designs and travel patterns.

Second, congestion charges may be seen as unfair from a "citizen" perspective. This would be the case if the support (or acceptability) of the fundamental underlying rationality or justification of congestion pricing differs across socioeconomic groups. For example, imagine a scarce resource which can be allocated through three alternative mechanisms: pricing, queueing or by some administrative/bureaucratic decision. Different individuals obviously prefer different mechanisms, for a variety of reasons, and the same individual may prefer different mechanisms in different contexts. Say 
that an individual can be labelled a "winner", from a citizen point of view, when her preferred allocation mechanism is the one that is used. Similarly, citizens can be labelled "winners" when societal decisions regarding, say, environmental regulations or tax progressivity are made in consistency with their preferences as citizens (which may or may not be aligned with their "consumer" interests). The question is now whether the share of "winners" on congestion pricing is different across (socio-)economic groups. This would be the case if congestion pricing is an "elite" project, which is more consistent with richer and/or more educated groups' views of what is fair, just or socially desirable. It is known from previous research that, ceteris paribus, support for congestion pricing is higher among individuals who rate environmental issues as important, and who perceive pricing as a fair allocation instrument. It is easy to imagine that high-income groups may view pricing as a fairer allocation mechanism than, say, administrative decisions - perhaps due to education, or self-interest, or social norms. It is also conceivable that high-income groups may place a relatively higher weight on environmental benefits. Whatever the reason, if this is the case, it would be reasonable to conclude that rich groups are "winners" from a citizen perspective, whether or not they are winners from a consumer perspective. These questions are discussed and analysed in the second part of the paper (section 4). Comparing results from the four cities again show striking similarities, despite different political cultures in general and framing of the congestion pricing issue in particular.

\section{Background and data}

The data in this study comes from a survey first designed by a Swedish-French-Finnish team of researchers, and carried out in Stockholm, Lyon and Helsinki in 2011 (Hamilton, Eliasson, BrundellFreij, Raux, \& Souche, 2014). Later, two waves of the survey (with some minor modifications) were carried out in Gothenburg in 2012 and 2013, i.e. both right before and almost one year after Gothenburg introduced its congestion pricing system (in January 2013) (Börjesson, Eliasson, \& Hamilton, 2016). The references provide more information about the data and its collection. The survey was presented as a general survey about several transport-related issues; to avoid policy bias, it was deliberately not presented as a survey specifically about congestion charges.

All the four cities are medium-sized cities with fairly typical European structures and transport systems. All have a historical city centre encircled by more recently populated areas. Around $80 \%$ of households have access to at least one car. Trips have a predominantly radial pattern, with the main flow of commuters moving inward in the morning and outward in the evening. Public transport shares vary, but are much higher than e.g. typical US levels in all the four cities. Transit fares are subsidized around $50 \%$. Stockholm and Gothenburg have operational congestion charging systems, whereas Helsinki and Lyon do not.

In the survey, respondents were asked how they would vote in a (hypothetical) referendum about congestion charges. Respondents were presented with different systems in the four cities. In Stockholm and Gothenburg, the question referred to the actual systems. The Stockholm system was introduced in 2006 , and consists of a cordon around the inner city where drivers pay $€ 1$ to $€ 2$ per passage (both directions) during weekdays, depending on time of day between 06.30 and 18.30. (The Stockholm experiences are further described in e.g. Eliasson (2008) and Börjesson et. al. (2012).) The Gothenburg system, introduced in 2013, consists of a cordon with three additional charging borders located as rays out from the cordon. Drivers pay $0.8 €-1.8 €$ per passage (in both directions) depending on the time of 
day, weekdays 06:00-18:30. (Traffic effects are described in Börjesson and Kristoffersson (2015), and public attitudes in Börjesson, Eliasson and Hamilton (2016).)

In Helsinki, the question referred to a proposed system intensively debated at the time of the survey. The system was supposed to be based on GPS units in all vehicles, with different tariffs per kilometre in two zones - an inner zone covering the central area in Helsinki, and an outer zone covering most of Helsinki. Political support for congestion pricing was never widespread, and at the time of the survey, it became clear that there was a decisive majority against its implementation. At present, there are no plans for implementing congestion pricing in Helsinki.

In Lyon, the question referred to a hypothetical system where all cars entering the urban centre would pay $3 €$ per day, independent of time of day or day of the week, with a maximum of $50 €$ per month.

Table 1. Description of the surveys.

\begin{tabular}{|l|c|c|c|c|c|}
\hline & Stockholm & Helsinki & Lyon & $\begin{array}{c}\text { Gothenburg, } \\
\mathbf{2 0 1 2}\end{array}$ & $\begin{array}{c}\text { Gothenburg, } \\
\mathbf{2 0 1 3}\end{array}$ \\
\hline Date & Spring 2011 & Spring 2011 & Spring 2011 & December 2012 & December 2013 \\
\hline Method & Postal & Postal & Telephone & Postal & Postal \\
\hline $\begin{array}{l}\text { Number of } \\
\text { responses }\end{array}$ & 1837 & 1178 & 1500 & 1582 & 1426 \\
\hline Response rate & $43 \%$ & $39 \%$ & $37 \%$ & $40 \%$ & $38 \%$ \\
\hline
\end{tabular}

The subsequent analyses are based on approximate monthly toll payments, calculated from respondents' own statements. In Stockholm, Lyon and Gothenburg, respondents were asked how often they paid the congestion charge (Stockholm and Gothenburg 2013) or would pay if they drove as today (Lyon and Gothenburg 2012), and this was converted into approximate monthly payments using data on the average payment per day. In the case of Helsinki, respondents were asked how many kilometres they drove in each zone on an average day, which was then also converted into an approximate monthly payment. Obviously, relying on respondents' own estimates of their toll payments introduces some uncertainty, so numerical results need to be treated with some caution. However, the general patterns in the results are robust enough that this is not a significant problem for the purposes of this paper.

\section{Consumer perspectives on the fairness of congestion pricing}

The standard economic welfare effects of congestion charges are made up of four parts: paid tolls, adaptation costs (adjusting one's travel pattern to the charges), the value of travel time gains and finally the benefit of the recycled revenues. In the first section, I will concentrate only on the equity effects of the paid tolls. This is admittedly only a partial analysis, but nonetheless a relevant one. Regarding adaptation costs, they generally make up a small part of the total welfare effect ${ }^{2}$. The value of travel time gains may be substantial, but unfortunately they are difficult to quantify based on our survey data; however, an attempt is made in the next subsection. Fortunately, previous research has shown that the amount of tolls paid is a good proxy for the total welfare effect, including adaptation costs and travel time benefits (Eliasson \& Levander, 2006; Eliasson \& Mattsson, 2006). The use of revenues, finally, is 
of absolutely crucial importance for the equity effects of congestion charging reform seen as a whole. However, how revenues are used can be seen as a separate issue, and it is illustrative to analyse the direct equity effects of congestion charges separately from the equity effects of the revenue use.

Hence, the first subsection analyses the incidence of toll payments across income groups in the four cities. In the second subsection, more variables relating to self-interest are introduced: the value of travel time savings, the number of car trips and the number of cars in the household.

\section{Incidence of toll payments across income groups}

\section{Distributional profile of toll payments}

The four systems differ considerably in their design, and in particular with respect to how much people [would] pay in tolls on average. Figure 1 shows how many who [would] pay different amounts in tolls, as a share of the region's population. In Stockholm, the share who pay high amounts in tolls is low, whereas in the suggested Helsinki and Lyon systems, large shares of the population would pay rather substantial amounts. The results from the Gothenburg system are interesting compared to Stockholm: although the charge per passage is lower than in Stockholm, the Gothenburg system affects a much larger share of the population, which makes the share of the population who pay high amounts much larger than in Stockholm.

Figure 1. Share of population who pay various amounts in tolls.

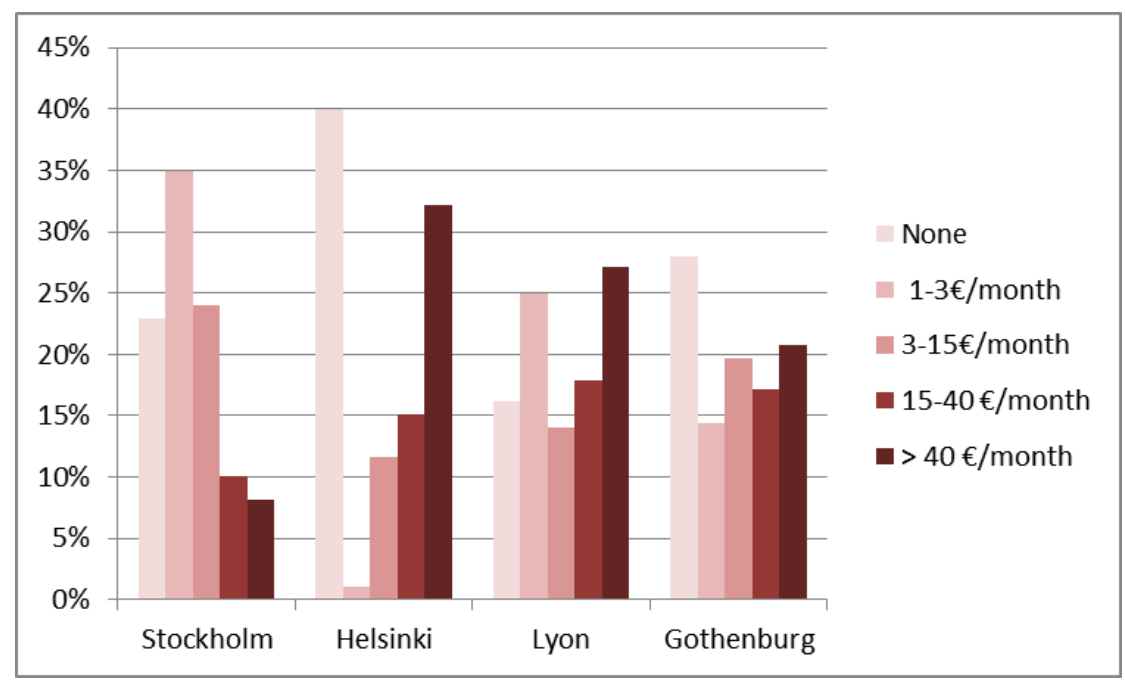

Figure 2 shows average toll payments per income group in the four cities. The left pane shows results in absolute numbers, while the right pane shows the results normalised by the average toll payment in each city, to facilitate comparison between cities. 
Figure 2. Average toll payments per income class.

Absolute numbers (left) and relative to average toll payment (right).
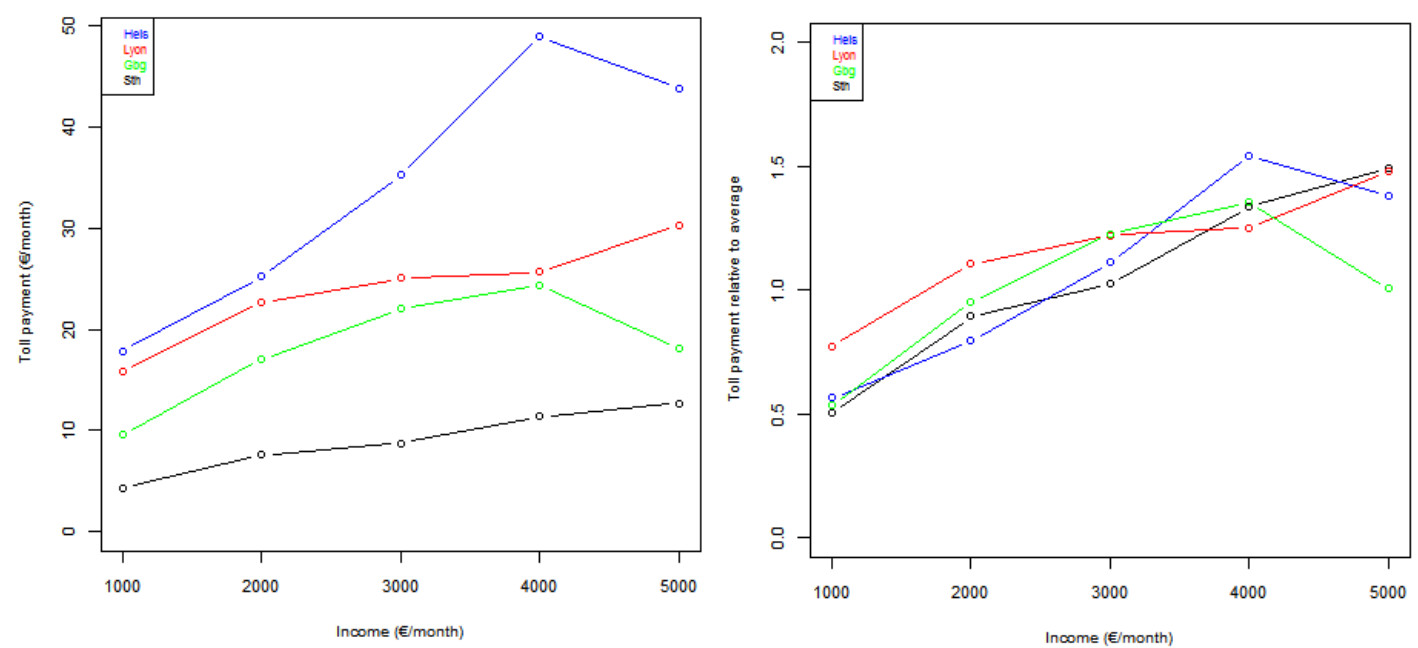

In all cities, high income groups pay much more than low income groups. Looking at the right pane, the differences across income groups are surprisingly similar in the four cities, despite the differences in system design and socioeconomic geography. In Gothenburg and Helsinki, however, the highest income group pay less than the middle groups. In Helsinki it is because the highest income group tend to live and work more centrally, and hence drive shorter distances on average. In Gothenburg, it is because company cars are exempt from congestion charges (according to Swedish tax law), and high income groups have access to company cars to a much larger extent. The company car exemption is discussed further below.

However, even if the poor pay less than the rich, they actually pay more relative to their income, as shown in Figure 3. The left pane shows average toll payments as a share of income ${ }^{3}$ for each income class, while the right pane shows the same thing but normalised to allow comparisons across cities.

Figure 3. Average toll payments as share of income, per income class.

Percentages (left), relative to average percentage (right).
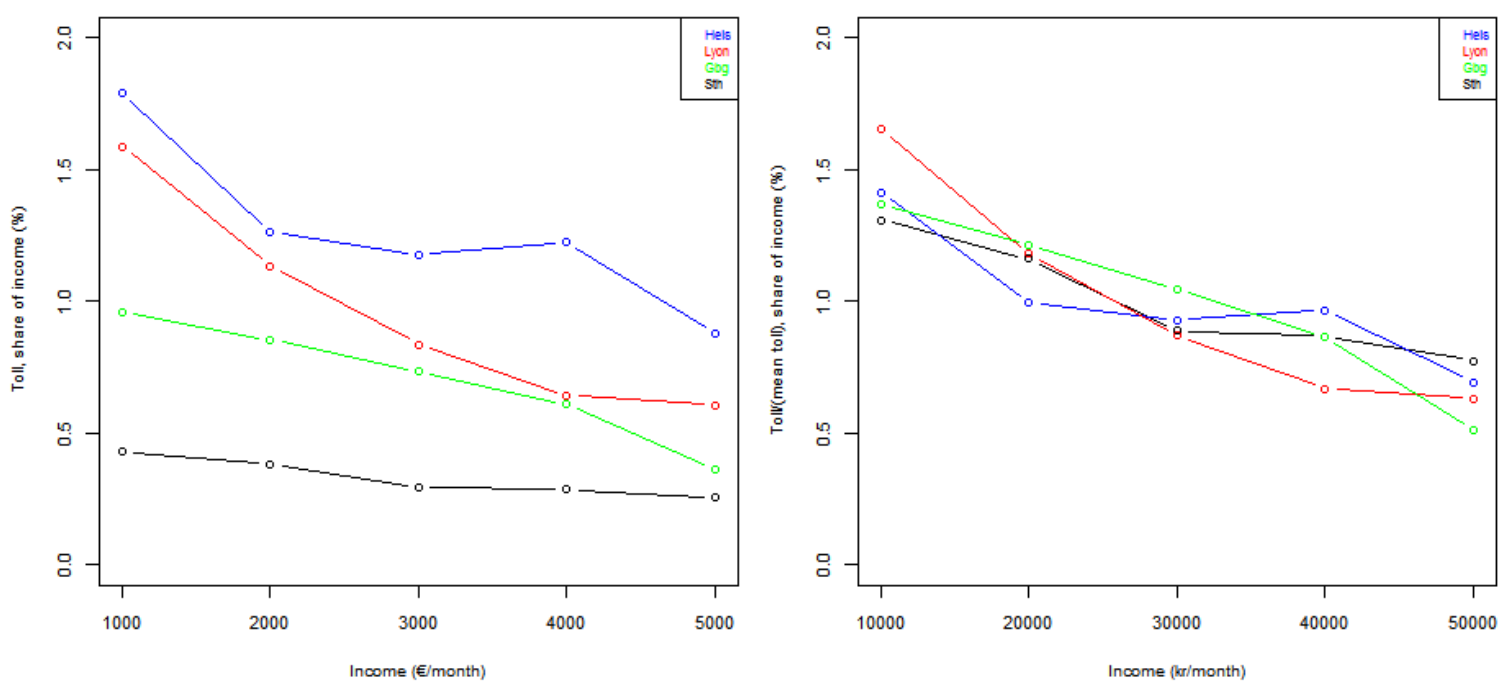
The figures reveal that the congestion charges are in fact regressive in all the cities - total payments relative to income falls with increasing income. The diagrams indicate that the regressivity seems to be largest in Lyon and smallest in Stockholm. A common measure of the overall regressivity of a tax instrument is the Suits index (Suits, 1977). A flat-rate tax has Suits index 0, a regressive tax has a negative Suits index and a progressive tax a positive index. The index is bounded between -1 and 1 . Table 2 shows the Suits indices for the four systems.

Table 2. Suits index (overall regressivity/progressivity) of the congestion charges

\begin{tabular}{|l|l|}
\hline City & Suits index \\
\hline Stockholm & -0.09 \\
\hline Helsinki & -0.09 \\
\hline Lyon & -0.16 \\
\hline Gothenburg & -0.13 \\
\hline
\end{tabular}

That congestion pricing is regressive in this sense is actually an expected result: a consumption tax will be regressive if the consumption elasticity with respect to income is lower than 1 . Even if driving (especially in the urban centres) increases with income, it usually increases less than proportionally to income, which means that most taxes on car driving will be (at least slightly) regressive. The Suits indices in Table 2 reveal that the analysed systems in Stockholm and Helsinki are slightly regressive, while the Lyon and Gothenburg systems are moderately regressive. For comparison, Metcalf (1996) calculates the Suits index of the US sales tax to -0.11; CPPP (2007) calculates Suits indices of the gas tax and sales tax in Texas to -0.25 and -0.18 , respectively; West (2004) calculate Suits indices of a US VMT tax and a size-differentiated vehicle tax to 0.14 and -0.30 , respectively; Eliasson et al. (2016) calculate Suits indices of the Swedish fuel tax and a differentiated vehicle tax to 0.03 and $\neg 0.09$, respectively.

\section{Are the distributional profiles fair?}

What, then, is the most appropriate definition of "fairness"? Is congestion pricing fair as long as the rich pay more than the rich? Or is it fair only when the poor pay a lower share of their income? This is a question without a clear answer, but a few things can be pointed out.

First, prices are usually the same for everyone, regardless of income or wealth (with the exception of a few deliberate exceptions such as subsidized healthcare and social housing). Prices of gasoline, cars, food, clothes, housing and so on do not vary with income ${ }^{4}$. The social desire for increased equality is instead usually handled by taxation and welfare systems. The fundamental reasons for redistributing income rather than letting prices depend on income are two: first, the government can then leave to each individual to choose how she wants to allocate her income on various goods, according to her own preferences; second, the price of each good will reflect its "value" in terms of scarcity and/or production cost, so having the same price for everyone will achieve a Pareto efficient outcome. Now, the purpose of a congestion charge is to correct the price of car driving for external effects, to make it better reflect the total social cost of car driving. In other words, the price for car driving with the congestion charge is what the price really should be; without the charge, driving is subsidised from a social point of view. From this perspective, it can in fact be argued that the distributional effects of introducing congestion pricing are irrelevant - that is, if one accepts that the default situation is that prices are equal for 
everyone, and should reflect the true, social cost for each good. At least, one should realize that arguing against corrective taxes with distributional arguments is logically equivalent to arguing that the good in question (car travel, for example) should be subsidized for distributional reasons - and this is often a much less persuasive or intuitively appealing argument.

Second, however, congestion charges may well have a strong fiscal motivation as well. The Gothenburg system is a good illustration: the system was designed to generate a revenue of at least 1 billion kronor $(100 \mathrm{M} €)$ per year to be used for infrastructure investments. As a secondary purpose, the system should decrease congestion as efficiently as possible, given this revenue constraint. In such cases, congestion pricing is clearly not only about correcting prices; the purpose is at least as much to generate public revenues. This makes it more appropriate to compare distributional effects of charges against income taxation; had the revenues not come from congestion charges, they would have had to come from the usual public tax sources. Hence, comparing toll payments relative to income is a natural default position in such cases.

Third, being aware of the distributional effects of any new policy is clearly important. Any change in prices causes transition costs which may be important to consider, at least for determining at which speed a change can be implemented. Moreover, real congestion pricing systems are not perfect - they do not, in reality, perfectly reflect the true social cost of each car trip due to technical or cognitive constraints; some car trips will actually be overpriced, while others will still be underpriced. In this perspective, it can be relevant to check how many drivers experience a substantial increase in travel costs, defining "substantial" in some suitable way. If this share is high, especially in low-income groups, it may be a warning signal indicating either that the policy may be too ambitious too fast, or that the design punishes some trips disproportionately.

Looking only at averages hides the fact that the variation within each income group may be substantial. Compare this to an income tax, which will by definition affect everyone with the same income in the same way. In the case of congestion charges, there may be subgroups who are hurt disproportionately relative to their income, even if the charge is progressive overall (or at least not very regressive). This is in fact often the most important argument of those arguing against congestion charges using distributional arguments: not that the policy is necessarily very regressive on average, but that there may be non-negligible subgroups who are hurt disproportionately.

With this in mind, Table 3 shows the share of each income group who [would] pay more than 40 $€ /$ month in congestion charges. In Stockholm and Gothenburg, the shares are (very) small in the lower income groups, although they may still be non-negligible of course. In the suggested Lyon and Helsinki systems, however, the shares are quite high even in the lowest income groups, meaning that there are quite a few people who would see their driving costs rise considerably even among the poor. Remember, though, that these systems were never properly evaluated and re-designed. The Helsinki system was a real suggestion, but never made it further than the initial political debate. The Lyon system was designed for the purpose of the survey. Hence, it seems that real congestion pricing systems can be designed to have a much smaller impact on travel costs.

Table 3. Share of each income class who [would] pay more than $40 € /$ month in congestion charges

\begin{tabular}{|l|c|c|c|c|c|}
\hline \multicolumn{1}{|c|}{$\boldsymbol{\text { /month }}$} & $\mathbf{1 0 0 0}$ & $\mathbf{2 0 0 0}$ & $\mathbf{3 0 0 0}$ & $\mathbf{4 0 0 0}$ & $\mathbf{5 0 0 0}$ \\
\hline Stockholm & $2 \%$ & $7 \%$ & $7 \%$ & $13 \%$ & $15 \%$ \\
\hline Helsinki & $15 \%$ & $26 \%$ & $35 \%$ & $53 \%$ & $47 \%$ \\
\hline Lyon & $18 \%$ & $31 \%$ & $36 \%$ & $37 \%$ & $48 \%$ \\
\hline Gothenburg & $7 \%$ & $18 \%$ & $29 \%$ & $32 \%$ & $22 \%$ \\
\hline
\end{tabular}




\section{Lessons from the Swedish company car exemption}

The Swedish company car exemption is an example of a generally important point, namely that the distributional effects of congestion charges depends on the specific design of the charging system, and that legal decisions may have unintended consequences. Some time after congestion charges had been introduced in Stockholm, the tax court determined that congestion charges were to be considered part of the operating costs of the car, and as such they were included in the "taxable benefit value" of a company car. This meant that company car owners either paid no charge at all, or could deduct the charge from their before-tax salary (which implied a substantial discount), depending on the company's policy. This was a completely unintended consequence of how the tax law interacted with the legal definition of the congestion charge (which, in legal terms, is a national tax) - but it had substantial effects on the distributional profile of the charges, especially in Gothenburg with its high prevalence of company cars in high income groups (the city is dominated by the car industry).

Figure 4 shows the effect of the exemption. Without it, the highest income group had paid the most; with it, the richest group pay on average as little as the second-lowest income group. Further, the regressivity had been much smaller without the exemption: the Suits index had been 0.06 rather than 0.13. The effect in Stockholm seems to be smaller, but unfortunately, there is so far no data available for Stockholm to analyse this in depth.

Figure 4. Average toll payments per income group, with company car exemption (black) and without (red).

Absolute numbers (left) and as share of income (right).
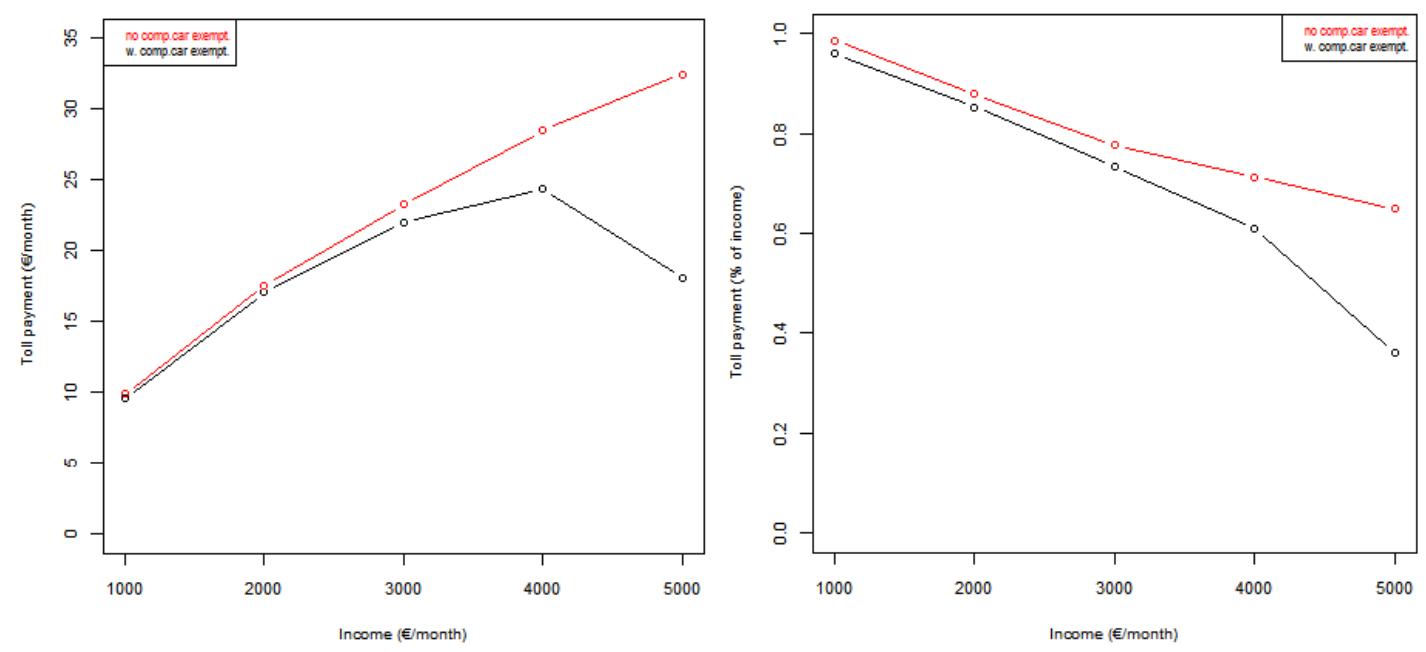

Tax rules for company cars are complicated in many countries, and the design of these rules may have profound and substantial effects on travel patterns and equity (see for example an analysis of a change in the UK tax rules by Le Vine et al. (2013)). As the Gothenburg example shows, it may drastically change the distributional profile of congestion pricing. More generally, the lesson is that exemptions of various kinds - for residents, professional traffic, certain residential areas and so on - may have important and perhaps unintended consequences both for the effectiveness and the distributional profile of congestion pricing. 


\section{Distributional effects in other dimensions}

In addition to income, congestion pricing can have distributional effects across other socioeconomic characteristics as well. Perhaps surprisingly, these differences are relatively small once income is controlled for. Detailed results are omitted to save space. The main differences across socioeconomic groups (controlling for income) are:

- In Lyon and Gothenburg, households with children under 18 years of age [would] pay more tolls (controlling for income) than households without children.

- In all cities except Gothenburg, men [would] pay more than women (even controlling for income differences). The difference is largest, in relative terms, for middle income groups.

- In Lyon, people older than 65 years would pay less (after controlling for income). In the other cities, differences across age groups are negligible.

- Education does not affect average toll payments in any systematic way.

\section{Broadening the perspective: Incidence of compound self-interest}

How much someone pays [would pay] affects the person's attitude to a suggested congestion pricing system: all else equal, people are more negative the more they [would] pay (e.g. Börjesson et al., 2016; Eliasson, 2014; Eliasson \& Jonsson, 2011; Gaunt, Rye, \& Allen, 2007; Hamilton et al., 2014; Hårsman \& Quigley, 2010; Jaensirisak, May, \& Wardman, 2003; Schade \& Schlag, 2003). Respondents were asked how they would vote in a referendum about congestion pricing, regarding the actual schemes in Stockholm and Gothenburg, the debated scheme in Helsinki, and a hypothetical area charging scheme in Lyon. The response alternatives were Certainly yes, Probably yes, Probably no, Certainly no or No opinion/I don't know. Answers clearly correlated with the amount of tolls respondents paid or would pay. Defining "support" as the share of positive responses excluding "No opinion/I don't know", Figure 5 illustrates how support depends on the [anticipated] toll payments.

Figure 5. Support for congestion pricing with respect to toll payments $(€ /$ month)

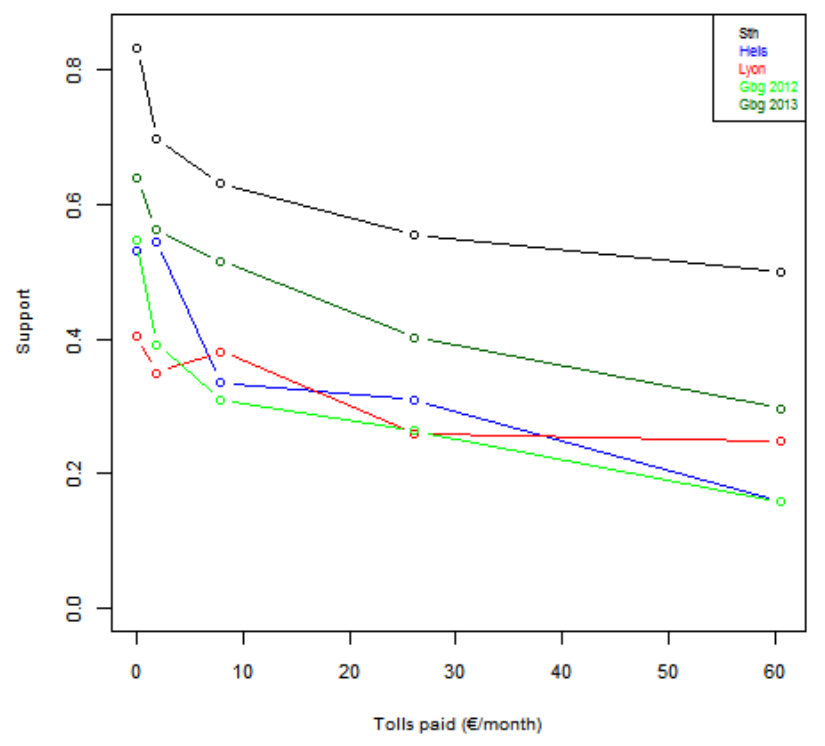


Clearly, support falls as toll payments increase. Note, however, that the biggest drop in support is between those who pay no toll at all (e.g. don't own a car) and those who pay something, albeit just a little (Lyon is an exception). It is interesting how similar the patterns are in the three cities without congestion charges: Helsinki, Lyon and Gothenburg in 2012 (before the system started). The figure also illustrates the "experience" effect in Gothenburg: the Gothenburg 2013 curve has moved upwards with almost precisely the same shift for all groups, regardless of toll payments (although the effect is slightly smaller for those who pay no toll at all).

In addition to toll payments, attitudes are also affected (as we shall see) by several other variables which are related to self-interest, and should hence be included in the consumer perspective: how many car trips a respondent makes, her value of travel time savings and how many cars there are in the household. That the number of cars and car trips significantly affect attitudes to congestion pricing even after controlling for toll payments may be for several reasons: it may reflect the general car dependency of the household or individual, for example.

The fact that there are more variables than just toll payments which affect attitudes to congestion pricing means that an analysis which only takes toll payments into account may not fully reflect the subjective benefits and losses of charges, as perceived by the individual. If the aim is to measure the incidence of congestion pricing as perceived by the individuals themselves, the analysis has to be extended to account for these other variables as well. After all, these variables also reflect various aspects of the perceived personal incidence of the congestion charges. I will call this total, perceived, personal incidence the compound self-interest, since it is the sum of several factors: tolls paid, time gains, adaptation costs and so on.

How, then, should these variables be weighted together? A natural approach is to estimate a statistical model of how they affect respondents' attitude to congestion charges, and take the estimated model parameters as relative weights of the different variables. In this way, the variables act as indicators of or proxies for different aspects in which congestion charges affect the individuals, which in turn allows for a richer analysis of the distributional effect of congestion pricing.

In addition, it is desirable to take into account that variables may affect different income groups differently. For example, it might be natural to expect that the same amount of toll payments might cause more disutility for low income groups than for high income groups, simply because low income groups might have higher marginal utility of income. Exploring the data, however, gives only limited support for this hypothesis. Figure 6 shows that there are only a few cases where it seems as if (high) toll payments affect attitudes differently across income groups. 
Figure 6. Support for congestion pricing in different income groups, split by those who pay little or nothing (black) and those who pay moderate or large amounts (blue).
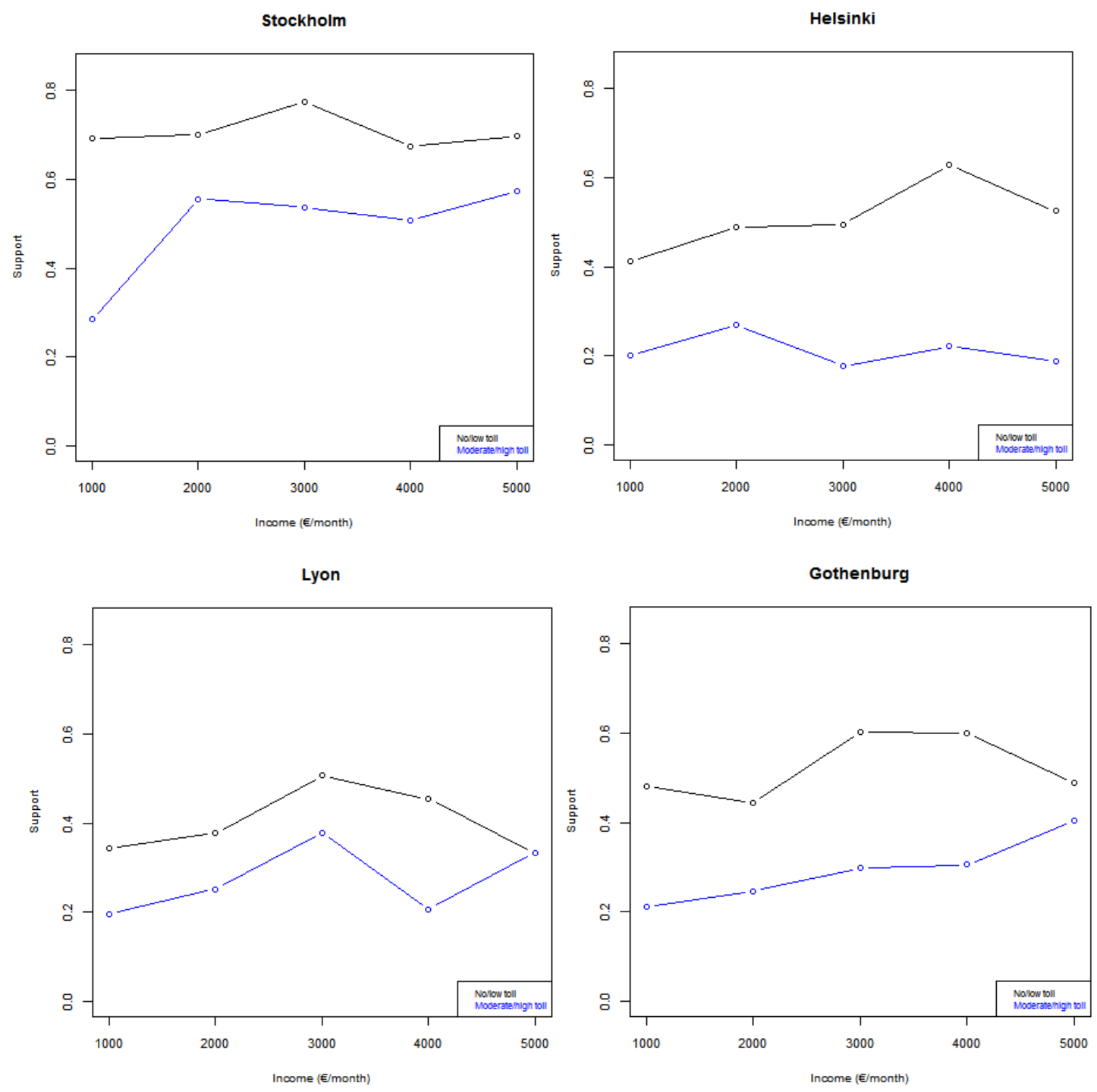

Cross-tabulations of this kind only give rough indications, of course. To properly separate the impact of different variables, respondents' attitude to congestion pricing (how they would vote in a referendum) is regressed on various self-interested-related variables. A potential problem with the model estimation is that attitudes are affected by several other variables as well - in particular other attitudes and if we omit these, the parameter estimates may be biased if there are correlations between included and omitted variables. Fortunately, however, this turns out not to be a problem: when attitude variables are introduced in the model (see next section), this does not change the parameters for the self-interest variables appreciably. Moreover, the general conclusions are robust for various other model specifications.

Since the voting response is an ordered variable, an ordered logit model is used. A comprehensive description of ordered models can be found in Greene (2003), but a short intuitive description is 
necessary. Let y be a latent (unobservable) variable, which is a linear function of a vector of observable variables $\mathrm{X}$, a parameter vector $\beta$ (to be estimated) and an idiosyncratic term $\varepsilon$

$$
y=\beta X+\varepsilon
$$

The latent variable y can be interpreted as a measure of how positive an individual is to congestion charges, which cannot be observed (measured) directly. What is observable is the voting response $\mathrm{z}$, which has five ordered levels $z=1, \ldots, 5$ from most negative to most positive. We assume that this response is determined by in which of five intervals y falls. The limits of the intervals are determined by estimated threshold parameters $\mu \_k$, so we have

$$
\begin{aligned}
& z=1 \text { if } y \leq \mu_{1} \\
& z=2 \text { if } \mu_{1} \leq y \leq \mu_{2} \\
& (\ldots) \\
& z=5 \text { if } \mu_{4} \leq y
\end{aligned}
$$

Assuming that $\varepsilon$ is logistically distributed, the probabilities that $\mathrm{z}=\mathrm{i}$ become

$$
\begin{aligned}
& P_{1}=1-\frac{1}{1+\exp \left(\mu_{1}-\beta X\right)} \\
& P_{i}=\frac{1}{1+\exp \left(\mu_{i}-\beta X\right)}-\frac{1}{1+\exp \left(\mu_{i-1}-\beta X\right)} i \in\{2,3,4\} \\
& P_{5}=\frac{1}{1+\exp \left(\mu_{4}-\beta X\right)}
\end{aligned}
$$

\begin{tabular}{|c|c|c|c|c|}
\hline \multicolumn{2}{|c|}{$\begin{array}{l}\text { To11s } \\
\text { To11s, add. inc.grp } 1 \\
\text { No car } \\
\text { Car trips } \\
\text { Value of time, drivers } \\
\text { Stockholm } \\
\text { Helsinki } \\
\text { Lyon } \\
\text { Gothenburg2014 }\end{array}$} & $\begin{array}{r}\text { value } \\
-0.0010832 \\
-0.0007957 \\
0.3061705 \\
0.4306097 \\
0.2389846 \\
0.9948645 \\
0.0213867 \\
-0.1766564 \\
0.5572110\end{array}$ & $\begin{array}{r}\text { Std. Error } \\
0.0001125 \\
0.0002209 \\
0.0610495 \\
0.0284951 \\
0.0189181 \\
0.0668150 \\
0.0740519 \\
0.0722816 \\
0.0697637\end{array}$ & $\begin{array}{r}t \text { value } \\
-9.6249 \\
-3.6030 \\
5.0151 \\
15.1117 \\
12.6326 \\
14.8898 \\
0.2888 \\
-2.4440 \\
7.9871\end{array}$ \\
\hline \multicolumn{5}{|c|}{ 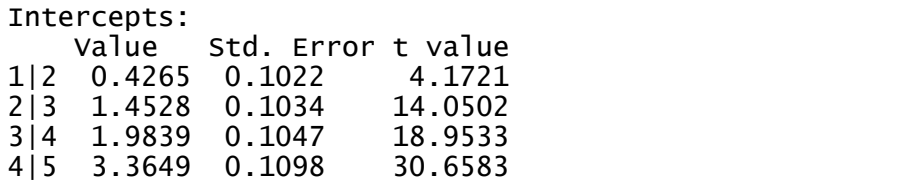 } \\
\hline \multicolumn{5}{|c|}{$\begin{array}{l}\text { Residual Deviance: } 19960.01 \\
\text { AIC: } 19986.01\end{array}$} \\
\hline
\end{tabular}

Table 4 shows the estimation results from the ordered logit model, indicating how respondents' attitude to congestion charges (as measured by the voting response) is affected by various self-interestedrelated variables. A large number of model specifications have been tested, but details are omitted to save space. Positive parameters indicate that support increases when the variable increases.

Table 4. Estimation results: impact of self-interest variables on attitude to congestion pricing.

Toll payments affect attitudes negatively; the effect is proportional to the amount of tolls paid. This effect is stronger for the lowest income group $(<1500 € /$ month) (the two "tolls" parameters are added), but there are in fact no significant differences among the other income groups. Not owning a car at all 
increases support more than can be explained merely by not having to pay tolls, so a dummy variable for "no car in household" is significant and positive. More car trips decrease support (with a linear effect), even after controlling for toll payments. The model also includes dummy variables for the different cities and for the difference in Gothenburg between 2012 and 2013; Gothenburg 2012 is taken as the reference level. The attitude differences between Gothenburg 2012, Lyon and Helsinki (neither of which had congestion pricing in place) are very small, while attitudes in Stockholm and Gothenburg 2013 (after congestion pricing was introduced) are much more positive.

Finally, the value of travel time savings has a substantial positive impact on support for those who make at least a few car trips per week. The value of travel time savings was measured with the following thought experiment:

You commute daily by car. On the way, you have to cross a bridge 5 across a river. One day, the bridge closes for repairs for a long time. Another bridge is available further downstream, but the detour takes an additional 20 minutes. During the time it takes to repair the bridge, the road authority has arranged with a ferry that can take cars over the river. What is the highest amount you would be prepared to pay for a one-way ticket for the ferry, to save 20 minutes on your journey to work?

Respondents were given seven alternative answers ranging from "nothing" to "more than $5 €$ ".

For our purposes, it is important to note that the impacts of the self-interest-related variables do not vary systematically across income groups (except for toll payments in the lowest income group). Surprisingly, the effect on attitudes of making one car trip more or paying one more euro in tolls and so on seems to be the same, regardless of income. A plausible hypothesis is that for the moderate monetary amounts we are considering, the differences in marginal utility of money are not large enough to matter for attitudes.

With the model results in hand, we can calculate a broader measure of the perceived incidence of congestion charges across income groups, simply by calculating the relative differences in the latent variable y across income groups. Note that this is an exploratory analysis where the numerical results must be interpreted with caution: there is no guarantee that y can be interpreted cardinally, or in other words, that the absolute magnitude of y is meaningful (since the "unit" of y may not be constant if the distances between thresholds are very different). However, comparing average values of y across income groups will give an indication whether some income groups can be said to be worse off ${ }^{6}$.

Figure 7 shows the distributional profile across income groups for the four cities. Results have been normalized for each city, since the purpose is just to compare the relative tendency across income groups for each city. (Let $y_{n}$ be the latent variable for individual $n$. The bar in the histogram corresponding to income group $i$ in city $j$ is $B_{j}^{i}=\frac{\sum_{n \in(i, j)} y_{n}}{\sum_{n \in j} y_{n}}-1$. In other words, the diagram shows how much better or worse off each income group of a city is, on average, compared to the average citizen in that city. (Remember that this measures only "self-interest" effects, weighted as individuals perceive the effects themselves, as measured by their voting response.) 
Figure 7. Average compound self-interest per income group, relative to the mean in each city

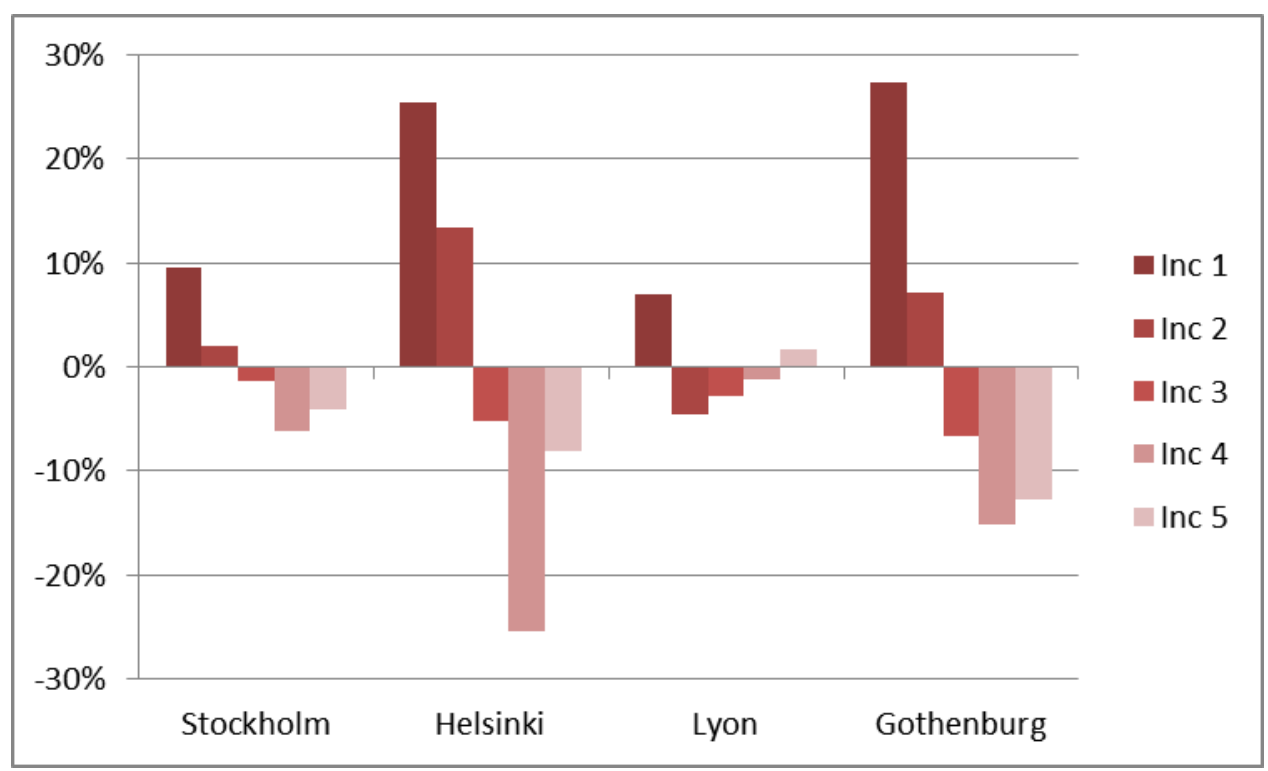

Except for Lyon, the pattern is the same in all cities: higher income groups are worse off, but the highest income group is in fact a little better off than the second-highest. This is partly due to this group having high values of time (on average), and partly due to average toll payments being lower than for the second-highest group due to central residential locations (Helsinki) or company car exemptions (Stockholm and Gothenburg). The relative differences across income groups are smaller in Stockholm than in Gothenburg and Helsinki. For Lyon, the distributional profile of the suggested system is different: the lowest income group is better off than the average, but after that, higher income groups are better off than lower income groups. The primary reason for this seems to be the design of the (hypothetical) Lyon system, where all car trips in the entire urban area is charged the same amount, regardless of time of day, destination or distance.

Broadly speaking, this shows that congestion pricing is "progressive" (with a slight abuse of the term) in the sense that lower income groups are hurt less by direct self-interest effects - as perceived by the individuals themselves, as measured by how self-interest variables influence voting response. The exception is Lyon, but the reason for this seems to be the coarse design of the system: a more realistic and efficient design may well have yielded other results. The lesson that can be drawn from Lyon is, again, that the design of the system is crucial for the distributional profile. 


\section{Citizen perspectives on the fairness of congestion pricing}

The previous section only dealt with fairness from a consumer perspective: how congestion pricing affects different income groups in terms of self-interest variables such as money, time and so on. This section analyses fairness from a citizen perspective. Different allocation mechanisms, and different social goals or benefits, can be viewed by citizens as "fair" in a more abstract sense. In this perspective, factors such as procedural justice, equity, equal treatments, human rights and the relative weights of different social objectives often matter (depending on the issue). Citizens' perceptions and definitions of fairness will vary, of course, and may well correlate with their self-interest - although the direction of causality is not always easy to establish - but this does not change the point that "fairness" is something that people apparently value in itself, even abstracting from their own self-interest.

Here, I will focus on one particular issue, namely whether the opinions of congestion pricing from this citizen perspective vary systematically across socioeconomic groups - in particular across income groups. In other words, is the concept of congestion pricing - the principle of allocating scarce road space according to willingness to pay - more consistent with, say, high-income groups' views of what is "fair" or "just" than with low-income groups' views? If so, one could reasonably argue that congestion pricing is an "elite" project, since the concept would be better aligned with what high-income groups view as a "fair" or "just" society. A priori, I see no particular reason to expect neither this nor the opposite; but I think the issue clearly matters for the socio-ethical or democratic justification of congestion pricing, and the fact that I do not know what result to expect a priori makes the question interesting.

Disentangling this question, however, is complicated. Obviously, simply asking respondents "is congestion pricing fair?" will elicit responses so tainted with self-interest that it is virtually pointless. Instead, our survey contained a large number of questions about whether respondents perceived various allocation mechanisms as "fair", and also questions about other social issues such as environment and income equity. Through econometric modelling (controlling for self-interest variables), we can then reveal how perceptions of these more or less related issues correlate with the attitude to congestion pricing, and finally measure how well aligned congestion pricing is with these related socio-political views.

The question of how perceptions of fairness and other social issues vary across income groups and cities is of course interesting in itself. Therefore, the first subsection explores this, before the second subsection turns to our main issue of citizen perspectives of congestion pricing.

\section{Opinions about fairness and related political issues}

Respondents were presented with a number of statements, and asked to indicate to what extent they agreed on a 7-grade scale, from "completely disagree" (-3) over "neither agree nor disagree" $(0)$ to "completely agree" $(+3)$. Table 5 shows how respondents in the four cities agreed, on average, with the statements. 
Table 5. Average agreement (from -3 to 3) with statements.

\begin{tabular}{|c|l|c|c|c|c|}
\hline & \multicolumn{1}{|c|}{ Stockholm } & Helsinki & Lyon & Gothenburg \\
\hline 1 & $\begin{array}{l}\text { "Considerably more resources should be used } \\
\text { to protect the natural environment." }\end{array}$ & 1.4 & 1.3 & 2.1 & 1.3 \\
\hline 2 & $\begin{array}{l}\text { "The government should prioritise to reduce } \\
\text { the differences between the poor and the rich } \\
\text { in the society." }\end{array}$ & 0.9 & 1.2 & 1.7 & 1.3 \\
\hline 3 & "Taxes in [country] are too high" & 0.8 & 1.2 & 1.3 & 0.3 \\
\hline 4 & Pricing the ferry is fair & 1.9 & 1.4 & 0.3 & 0.9 \\
\hline 5 & Queueing to the ferry is fair & 1.5 & 2.1 & -1.2 & 0.8 \\
\hline 6 & $\begin{array}{l}\text { Letting a public agency decide about space on } \\
\text { the ferry is fair }\end{array}$ & 0.1 & -1.1 & -1.6 & -0.7 \\
\hline 7 & $\begin{array}{l}\text { Giving out places on the ferry with a lottery is } \\
\text { fair }\end{array}$ & -1.1 & -1.3 & -2.3 & -2.2 \\
\hline 8 & $\begin{array}{l}\text { "It is fair [justified] that airplane tickets cost } \\
\text { more for departure during peak hours than } \\
\text { during off-peak" }\end{array}$ & 0.9 & 0.8 & -0.4 & 0.3 \\
\hline 9 & $\begin{array}{l}\text { "It is fair [justified] that airplane tickets to } \\
\text { vacation destinations cost more when the } \\
\text { weather in [country]is bad." }\end{array}$ & -1.0 & -1.2 & $\mathrm{n} / \mathrm{a}$ & -1.4 \\
\hline 10 & $\begin{array}{l}\text { "It would be fair [justified] if transit fares } \\
\text { were lower in off-peak hours" }\end{array}$ & 1.0 & 0.6 & 0.7 & 0.9 \\
\hline
\end{tabular}

Statements (1)-(3) are about general political issues: environment, social equity and taxes. Respondents broadly agree with the statements, on average. Almost no one disagrees with the environment statement (2). Swedish respondents agree less with the statement that taxes are too high (3). Comparing Stockholm and Gothenburg, more respondents in Gothenburg agree with the equity question (2) and disagree with the "taxes are high" question (3).

Statements (4)-(7) are perhaps the most interesting and relevant in the context of this paper. Following the thought experiment about a ferry replacing the broken bridge (see section 3.2), respondents were given the following question:

Some people complain that it is unfair that the authority charges a price for the ferry tickets. When offering the ferry for free, it turns out that there is not room on the ferry for everyone who wants to use it. The authority now considers four different methods to choose who gets to travel with the ferry:

- Price: Revert to the original policy of charging those who want to travel, and set the price so the ferry is just filled.

- Queue: Those who arrive first to the jetty and stand first in line get to go with the ferry.

- Authority determines "need": Those who want to travel with the ferry have to show some evidence to support their need. The authority then provides ferry passes based on their judgment of the greatest need.

- Lottery: Tickets are allocated randomly, so that everybody has an equal chance of winning.

To what extent do you consider these alternatives fair? [7 grade scale from "Completely unfair" $(-3)$ to "Completely fair" $(+3)]$ 
In almost all cities, respondents rate the fairness similarly: pricing comes first, followed by queueing and then decisions by a public authority, with lottery as a distant fourth. Helsinki differs in that queueing is ranked as fairer than pricing. However, answers vary considerably across countries, and are actually in line with some clichés about national political cultures. French respondents rate all alternatives lower than respondents from other countries; in fact, 25\% of French respondents rate all allocation mechanisms as more or less unfair (below 0 ) and 17\% rate all allocation mechanisms as "very" or "completely" unfair (begging the question if there is any "fair" mechanism to allocate space on the ferry). Swedish respondents seem to put more trust in public authorities (which is consistent with many other studies), rating decisions by a public agency as fairer than respondents from other countries do.

Statements (8)-(10) concern various forms of scarcity pricing in other contexts. Differentiating air fares (8) and transit fares (10) with respect to peaks in demand is rated "fair" by a narrow majority of respondents in most cities - although in all cities, there are sizeable groups who rate this as unfair. However, commercial airlines taking advantage of increased demand due to bad weather strikes a majority of respondents as unfair. One interpretation is that there is a difference in perceived fairness of pricing between situations when supply is "necessarily" scarce - such as airport and transit capacity in peak hours - and situations where commercial companies simply extracts an increased willingness to pay.

For the purpose of this paper, the most interesting question is whether the answers vary systematically with income - in particular, whether views of the fairness of allocation mechanisms (including pricing) do. Table 6 shows correlations between income and agreeing with the statements.

\section{Table 6. Correlation between income and agreement with the statement}

\begin{tabular}{|c|c|c|c|c|c|}
\hline & & Stockholm & Helsinki & Lyon & Gothenburg \\
\hline 1 & $\begin{array}{l}\text { "Considerably more resources should be used } \\
\text { to protect the natural environment." }\end{array}$ & -0.06 & -0.10 & -0.02 & -0.04 \\
\hline 2 & $\begin{array}{l}\text { "The government should prioritise to reduce } \\
\text { the differences between the poor and the rich } \\
\text { in the society." }\end{array}$ & -0.19 & -0.27 & 0.00 & -0.17 \\
\hline 3 & "Taxes in [country] are too high" & 0.06 & -0.03 & -0.01 & 0.02 \\
\hline 4 & Pricing the ferry is fair & 0.00 & 0.01 & 0.01 & 0.02 \\
\hline 5 & Queueing to the ferry is fair & -0.08 & -0.03 & 0.03 & -0.05 \\
\hline 6 & $\begin{array}{l}\text { Letting a public agency decide about space on } \\
\text { the ferry is fair }\end{array}$ & 0.02 & 0.01 & -0.02 & 0.01 \\
\hline 7 & $\begin{array}{l}\text { Giving out places on the ferry with a lottery is } \\
\text { fair }\end{array}$ & -0.05 & -0.02 & 0.01 & -0.02 \\
\hline 8 & $\begin{array}{l}\text { "It is fair" [justified] that airplane tickets cost } \\
\text { more for departure during peak hours than } \\
\text { during off-peak" }\end{array}$ & 0.09 & 0.01 & 0.03 & 0.13 \\
\hline 9 & $\begin{array}{l}\text { "It is fair [justified] that airplane tickets to } \\
\text { vacation destinations cost more when the } \\
\text { weather in [country]is bad." }\end{array}$ & 0.09 & 0.02 & $\mathrm{n} / \mathrm{a}$ & 0.11 \\
\hline 10 & $\begin{array}{l}\text { "It would be fair [justified] if transit fares } \\
\text { were lower in off-peak hours" }\end{array}$ & 0.00 & -0.06 & 0.02 & -0.03 \\
\hline
\end{tabular}

The most striking result is that the correlation between agreement and income is generally very low. The main exception is only that low income groups agree much more with the equity question (2) (except in Lyon). Particularly surprising is the small differences across income groups in how respondents rate 
the fairness of pricing mechanisms $(4,8,9,10)$ and whether taxes are too high (3). In Sweden, highincome groups have a slight tendency to agree more with air pricing questions $(8,9)$ and that taxes are too high, but the tendency is small. More detailed analyses, also considering the tails and asymmetries of the distribution of answers, reveal a few more observations:

- Rich tend to agree more that having higher airfares in peak hours (8) is fair/justified. In particular, the share who agree strongly with the statement is higher in rich groups.

- Rich tend to agree slightly more that it is fair/justified that airfares to vacation destination are higher when the weather is bad (9). In particular, the share who strongly disagree is smaller among rich groups.

- In all cities except Helsinki, opinions about taxes (2) follows a U-shaped pattern: the two lowest income groups agree the most with that taxes are too high, but the highest income group agree more with this statement than the two middle income groups. In Helsinki, there is no correlation between income and opinions about taxes.

- Slightly fewer among the rich think that more resources should be spent on protecting the environment. In particular, fewer of the rich agree strongly; almost no one, in any income group, disagrees with the statement. In Stockholm and Gothenburg this tendency is small, whereas it is considerable in Lyon and Helsinki (the share who agree strongly $(\geq 2)$ falls from $80 \%$ in the poorest group to $60 \%$ in the richest group in Lyon, and from $60 \%$ to $40 \%$ in Helsinki).

- Comparing which way to allocate space on the ferry is rated as the fairest by each individual reveals that a higher share of the rich rates pricing highest on the fairness scale. The difference is not big, however: in Stockholm, where this difference is largest, 50\% in the richest group rate pricing as most fair, whereas $37 \%$ in the poorest group rate pricing as most fair.

- Conversely, slightly more in the poor groups rate allocating ferry space by a public authority as the most fair. More of the rich strongly disagree that this is a fair allocation mechanism. (There are no differences in how queueing is rated, however.)

- As already noted, a large share of French respondents rate all alternatives to allocate ferry space as unfair (in the other countries, this share is negligible - less than $2 \%$ of respondents). There is no difference across income groups in this respect.

Summing up these findings, a higher share of the poor agree with the equity statement (2), and a slightly higher share among the rich regard pricing as a fair allocation mechanism. On average, slightly fewer of the rich express strong environmental concerns (1). With these findings in hand, the next section explores correlation between these attitudes and the support for congestion pricing.

\section{Citizen perspectives on congestion pricing}

The main purpose of this section is to explore how "citizen" perspectives of congestion pricing vary across income groups, as explained above. An obvious place to start is to check whether the support for congestion pricing varies across income groups. As Figure 8 reveals, this is not the case: there is no particular systematic tendency in how different income groups would vote about congestion charges. 
Figure 8. Support for congestion charges across income groups in different cities (two different years in Gothenburg).

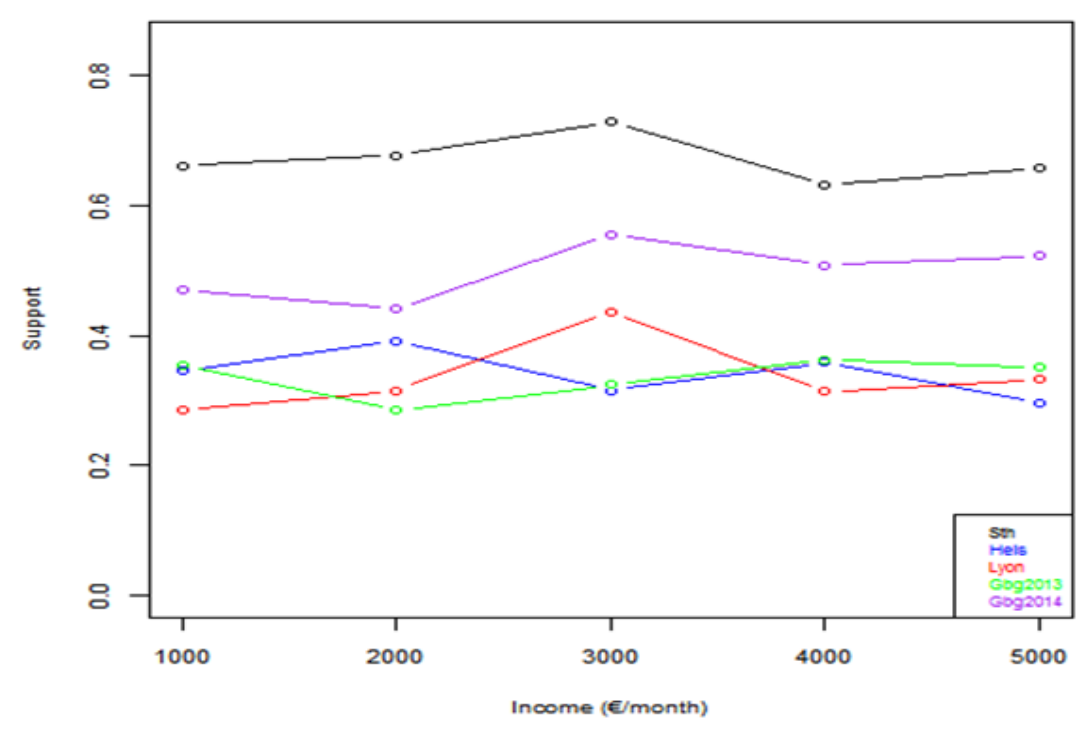

However, these aggregate figures do not reveal enough, since voting responses are affected by a mixture of self-interest and other considerations. Instead, we estimate a revealing how the attitude to congestion pricing is affected both by self-interest variables and by a number of variables representing citizen perspectives. Since several of the attitude questions (Table 5) measure similar things (in particular the attitude to scarcity pricing in different contexts), a subset of these indicators has to be selected. After testing various options, the following variables are included in the model: environment (agreement rating of statement (1) in Table 5), equity (statement 2), taxes are too high (statement 3), pricing is fair (4) and agency decision is fair (6). All these variables can be expected to correlate with the attitude to congestion pricing. To what extent they do may depend on how congestion pricing is perceived or framed in the local public debate or discourse. For example, if congestion charges are perceived as "just another tax", then the correlation with the attitude to taxes can be expected to be strong; if congestion charging is perceived as an environmental policy, then the correlation with the attitude to environmental policy can be expected to be strong - and so on. Table 7 shows estimation results from the ordered logit model (a binary logit model distinguishing only positive/negative answers give similar results).

Table 7. Variables affecting voting response (ordered logit)

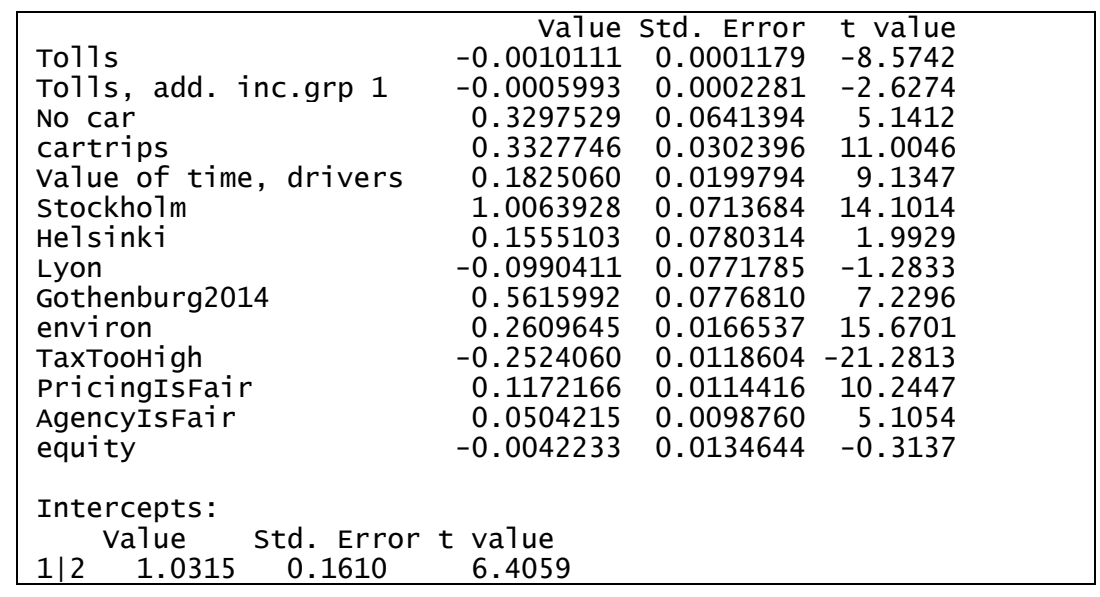




\begin{tabular}{|c|c|c|c|}
\hline \begin{tabular}{l|l}
2 & 3 \\
3 & 4 \\
4 & 5
\end{tabular} & $\begin{array}{l}2.1687 \\
2.7289 \\
4.2695\end{array}$ & $\begin{array}{l}0.1627 \\
0.1639 \\
0.1684\end{array}$ & $\begin{array}{l}13.3295 \\
16.6526 \\
25.3584\end{array}$ \\
\hline \multicolumn{4}{|c|}{$\begin{array}{l}\text { Residual Deviance: } 17698.47 \\
\text { AIC: } 17734.47\end{array}$} \\
\hline
\end{tabular}

The parameters of the self-interest variables are broadly unchanged by the introduction of attitude variables. The first four are highly significant: environment and pricing is fair is associated with more positive attitudes, while taxes are too high is associated with a more negative attitude. Authority decision is fair is also associated with more positive attitudes, although this effect is smaller. At first this may seem counterintuitive: after all, approving of authority decisions based on subjective "need" may seem like the opposite to approving of market-based solutions based on willingness to pay. However, what this question measures is rather the trust in government - whether the respondent believes that public agencies are, on average, trustworthy. Previous research has shown that support for congestion pricing correlates with trust in government and also supporting various kinds of public interventions (e.g. speed cameras).

Two negative findings in the model estimation are interesting. First, the equity variable is not significant (in any of the cities): there is, surprisingly, apparently no correlation between respondents' opinions about equity and their opinions about congestion pricing. In the light of this, the preoccupation with congestion charges' equity effects is rather remarkable - unless it is simply because supposedly negative equity effects is a more convenient argument against congestion charges in public debate than self-interest arguments. Second, there are no differences in the parameters for the attitude variables across income groups. In other words, attitudes affect voting responses in the same way, regardless of income. It might have been natural to expect that, for example, rich groups could "afford" to let, say, environmental concerns affect their attitude to congestion pricing more than poor groups - but this is apparently not the case.

The model in Table 7 shows how self-interest variables and the various "citizen perspective" variables are weighted against each other. This means that we can now interpret the underlying latent variable as an extended "utility function" comprising two parts: a consumer part (consisting of the selfinterest variables) and a citizen part (consisting of the citizen perspective variables). Note that this is an exploratory analysis, and the same caveat applies as noted previously: there is in principle no guarantee that the latent variable can be interpreted cardinally. However, exploring its average over income groups will give an indication of how attitudes are affected by consumer and citizen aspects, and how this varies across income groups. The robustness of the conclusions has also been checked with two other methods (a binary logit model and a predicted-response method; see endnote 5). 
Figure 9. Consumer and citizen components of the "utility" of congestion pricing, separated by income group

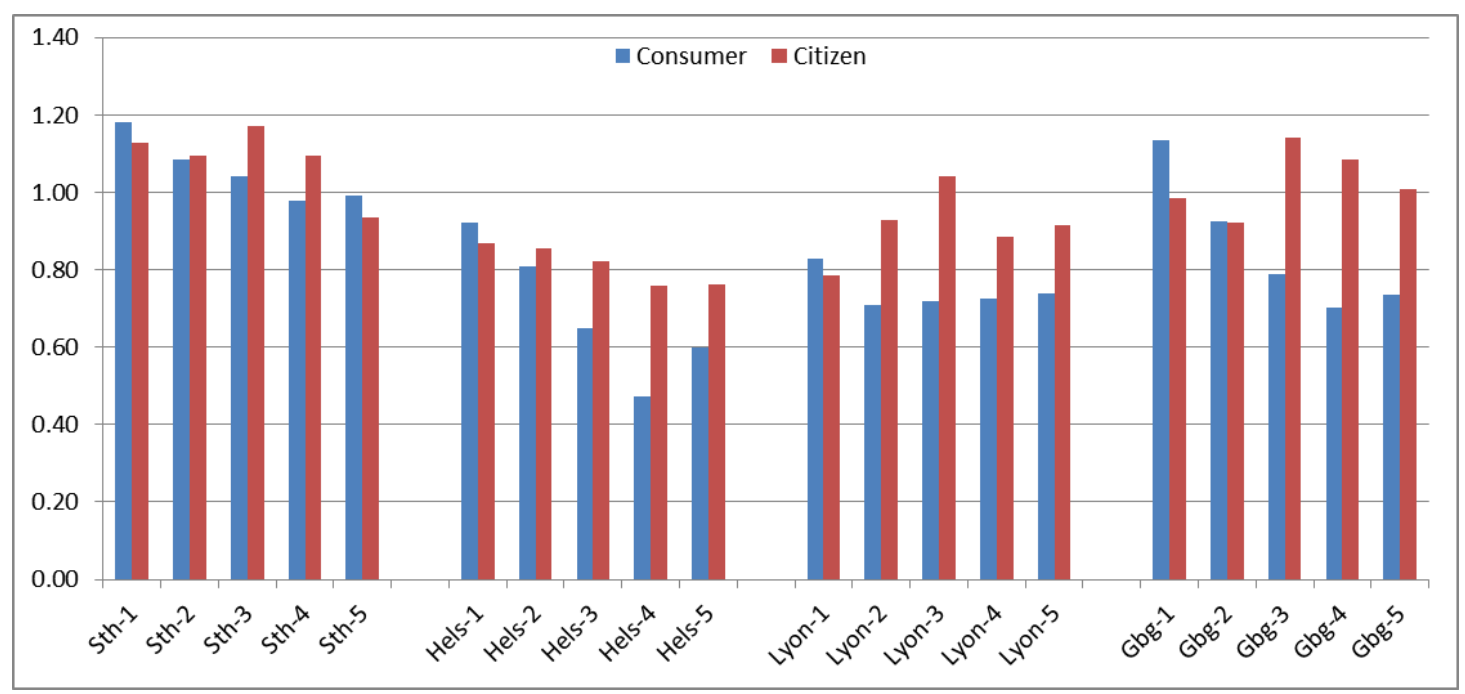

Figure 9 illustrates the citizen and consumer components of this "extended utility function" of congestion pricing. The blue bars (the "self-interest" or "consumer" component) are essentially the same as in the analysis of compound self-interest (Figure 7) but not rescaled with the average in each city. As was noted before, the general tendency is that low-income groups fare better compared to the average in each city in terms of the self-interest component, although the highest income group actually fare better than the second-to-highest.

The red bars - the "citizen" part - is the new part. Remember that this part of the "utility" function can be interpreted as how well congestion pricing is aligned with individuals' opinions about environmental policy, fairness of pricing as an allocation instrument, the level of taxation and trust in government. An individual who scores highly on these attitudes will tend to be a "winner" in a citizen sense (controlling for the self-interest component) if congestion pricing is introduced, in an analogous way as an individual with high value of time, low toll payments and so on will be a "winner" in a consumer sense (controlling for the citizen component)

The citizen effects are clearly different across income groups. Except for Helsinki, the general tendency is that the middle income group "wins" more than the low- and high-income groups. In Helsinki, income groups simply "win" more the lower income they have.

To explain this in more detail, Figure 10 separates the "citizen utility" into its subcomponents. Analysing this in detail shows that the reason that middle-income groups are "winners" from a citizen perspective is primarily because they are the most content with current tax levels, and also rate environmental concerns highly (on par with the lower income groups but slightly higher than the two highest income groups). It is also evident that the attitude variables, taken separately, have a very strong impact on attitudes. Whether congestion pricing is perceived as, for example, mostly an environmental policy or mostly as a tax will hence have a vast impact on support for congestion charges. 
Figure 10. Consumer and citizen components of the "utility" of congestion pricing, with "citizen utility" separated into its subcomponents, and separated by income group

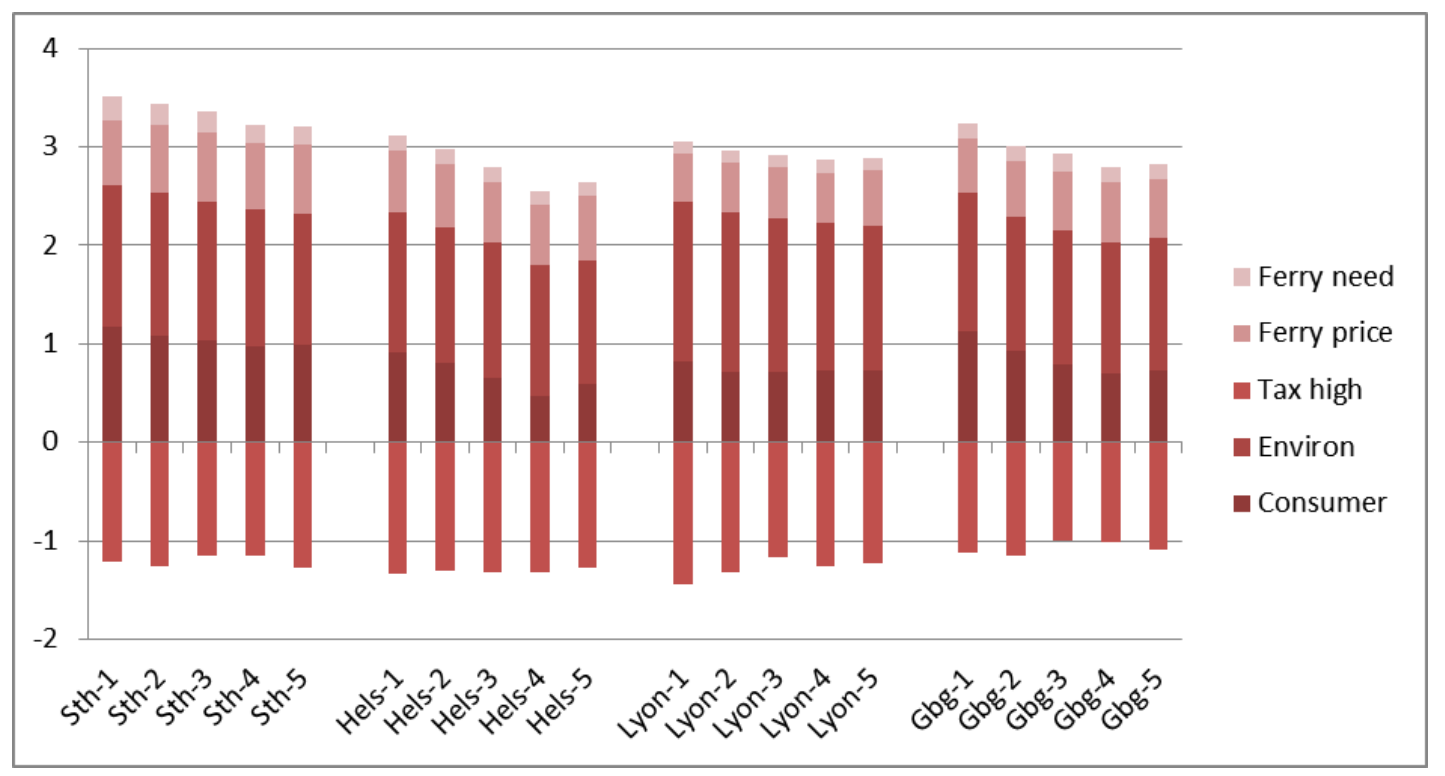

\section{Is congestion pricing fair from a citizen perspective?}

Given these results, can congestion pricing be considered "fair" from a citizen perspective? My conclusion would be a qualified "yes". Clearly, congestion pricing is not more aligned with the citizen preferences of the "elite", defined as the high(est) income groups. In three of the case cities, it is the middle income group who seem to "win" the most in a citizen perspectives; put differently, if is in this group that congestion pricing most closely aligns with the group's societal preferences. Perhaps the most important result, however, is that most differences in citizen preferences are small or negligible across income groups. Consequently the distribution of "citizen utility" is rather similar across groups.

The only social issue where there is a clear difference in opinions across income groups is equity. Lower income groups agree to a much larger extent that society needs to prioritise to reduce the gap between rich and poor. However, this turns out not to be related to the congestion pricing issue: there is no correlation between views of equity in any of the case cities.

\section{Conclusions}

The purpose of this paper has been to discuss and analyse to which extent congestion pricing can be viewed as fair. Since "fairness" can be interpreted in several different ways, a range of different analyses have been presented.

Starting with the consumer perspective on fairness, the incidence of toll payments is strongly correlated with income: high-income groups pay more in tolls, on average, in all cities. However, since car driving tends to increase less than proportionately with income, low-income groups tend to pay more tolls relative to their income, on average. A Suits index calculation shows that all of the four analysed congestion charging systems are regressive. Whether this is a problem depends, in my view, on the 
purpose of the charges. If the purpose is truly to correct the price of car driving, to make it reflect the full social cost of driving, then it is in fact doubtful whether distributional effects are relevant, at least in the long run. Amending income inequalities through taxation and welfare systems is both more effective and efficient than subsidising goods; and allowing prices to be lower than the social cost is equivalent to a social subsidy. However, congestion charges often have dual purposes: in addition to being a corrective tax, the purpose is often also (and sometimes primarily) to generate revenues, often for infrastructure investments. To the extent that the charges is a fiscal measure, the potential regressivity of congestion charges is a serious problem. After all, it is difficult to see why the poor should contribute more than proportionately to public tax revenues.

The distributional profile of congestion pricing depends on the design of the specific system location of charging points or areas, exemptions, time of day and so on. An illustrative example is the Swedish (unintended) exemption for company cars, which turned the Gothenburg system from an almost equity-neutral to a clearly regressive system.

In a second analysis, the consumer perspective was broadened from merely toll payments to a range of variables relating to self-interest: access to car in the household, value of time savings and the number of car trips. The weights of the different variables were obtained by estimating their impact on individuals' attitudes to congestion charges (how they would vote in a congestion pricing referendum). One interesting finding is that income hardly matters for how these variables affect attitudes to congestion charges; their impact on attitude is almost the same across all income groups (except the lowest group). With these weights, a compound self-interest measure was calculated, and its incidence across income groups was explored. Broadly speaking, this analysis showed that congestion pricing is "progressive" (with a slight abuse of the term) in the sense that lower income groups are hurt less than average by the direct, self-interest effects, as perceived by the individuals themselves. The exception is Lyon, but the reason for this seems to be the coarse design of the system: a more realistic and efficient design may well have yielded other results.

Fairness can also be viewed in a citizen perspective. Depending on individuals' views of procedural fairness, equity, environmental issues and so on, congestion pricing can be viewed as more or less "fair" in an abstract sense, disregarding its objective, "consumer" effects. A "winner" on a congestion pricing reform in a citizen sense is hence someone who approves of the underlying, abstract logic and rationale of congestion pricing - whose views of fairness, environment and other societal dimensions are aligned with what congestion pricing represents (for that individual). In order to estimate this "citizen utility", a model was estimated that separated how self-interest variables and attitude to various societal issues environment, taxes, pricing as an allocation instrument, equity and trust in government - affected attitudes to congestion pricing. This allowed for an even broader definition of the "utility" of a congestion pricing reform, capturing both consumer and citizen components. The distribution of these "utility components" across income groups can then be explored.

This analysis showed that in terms of "citizen utility", it is in fact middle-income groups who fare better than average, with the exception of Helsinki, where groups fare better (relative to the average) the lower their income is. Differences across income groups are relatively small, however.

In summary, it is hard to find much support of the view that congestion pricing is unfair, as long as its purpose is to correct prices and allocate scarce resources. Both in terms of absolute payments and compound self-interest, lower income groups fare better than average. From a citizen perspective, differences are small, but lower income groups fare at least as well (and in some cases better) than highincome groups. This changes, however, if the purpose of a charging system is in fact to generate revenues. In that case, the regressivity of the pricing systems - that poor pay more relative to their income - is a serious problem: it is difficult to defend that poor groups should contribute more than proportionately to public revenues. 


\section{Notes}

1. Other terms for essentially the same distinction are "homo economicus" vs. "homo politicus", or "personal well-being" vs. "subjective social welfare".

2. It can be shown that the relative size of the adaptation cost to the tolls paid, i.e. the "triangle under the demand curve" relative to the "rectangle under the demand curve" (ignoring changes in travel time for the moment), given a relative price change a and demand elasticity $\epsilon$ is $a \epsilon / 2$. To illustrate magnitudes, assume that a congestion charge increases the monetary cost of an average car trip by $25 \%$, and that the demand elasticity is in the order of -0.5 . This would give an adaptation cost which would be around $6 \%$ of the toll paid. More careful quantitative analyses, separating welfare effects into time gains, adaptation costs and paid tolls can be found in Eliasson (2009) and Eliasson and Levander (2006).

3. This is the average toll payment per income class divided by the average income in that class, which is the resolution available in the data. An alternative measure would be the average of (toll payment divided by income), but this causes problems for people with (notional) very low or even zero incomes.

4. This view is not shared by all, though. At the time I am writing this, a representative of the Swedish Left party is quoted in a newspaper saying "Uniform pricing of trips is a necessary fairness reform. Healthcare costs the same for everyone: travelling should, too." However, it turns out that the view that all trips should cost the same apparently only applies to public transport trips: the Left party is very much in favour of congestion charges.

5. In Lyon, the hypothetical situation instead involved a closed tunnel, as this was judged to be closer to reality and easier to imagine.

6. To check the robustness of the conclusions from this exploratory analysis, two other methods are also used. First, a binary model is estimated, grouping the responses into positive or negative, discarding "no opinion". This reduces the problem with different distances between thresholds, since there will, in essence, only be one "threshold". The parameters of this binary model turn out to be close to the ordered logit model, so conclusions stay unchanged. Second, the ordered logit model is used to predict the responses of all the individuals, using only these self-interest variables. This will be a measure of how individuals "should" vote if they only took self-interest into account. (Note that the reasons that this is meaningful is that the model does not incorporate constants for each income group; in that case, the model predictions had simply coincided with the actual average voting responses for each income class.) There is also, as noted above, a risk that parameters are biased since attitudinal variables are omitted. To check that, results are also compared with the model presented below where attitudinal variables are included. It turns out that the parameters of the "self-interest" variables hardly change.

7. The word "fair" is, it turns out, not always easy to translate. The Swedish survey used the word rimlig which can also be translated as "reasonable", "acceptable", "justified". 


\section{References}

Börjesson, M., Eliasson, J., \& Hamilton, C. (2016). Why experience changes attitudes to congestion pricing: The case of Gothenburg. Transportation Research Part A: Policy and Practice, 85, 1-16.

Börjesson, M., Eliasson, J., Hugosson, M. B., \& Brundell-Freij, K. (2012). The Stockholm congestion charges -5 years on. Effects, acceptability and lessons learnt. Transport Policy, 20, 1-12.

Börjesson, M., \& Kristoffersson, I. (2015). The Gothenburg congestion charge. Effects, design and politics. Transportation Research Part A: Policy and Practice, 75, 134-146.

Center for Public Policy Priorities. (2007). Who pays Texas taxes? ( No. No. 287). Center for Public Policy Priorities.

Eliasson, J. (2008). Lessons from the Stockholm congestion charging trial. Transport Policy, 15(6), 395404.

Eliasson, J. (2009). A cost-benefit analysis of the Stockholm congestion charging system. Transportation Research Part A: Policy and Practice, 43(4), 468-480.

Eliasson, J. (2014). The role of attitude structures, direct experience and framing for successful congestion pricing. Transportation Research A, 67, 81-95.

Eliasson, J., \& Jonsson, L. (2011). The unexpected "yes": Explanatory factors behind the positive attitudes to congestion charges in Stockholm. Transport Policy, 18(4), 636-647.

Eliasson, J., \& Levander, A. (2006). Equity Effects of the Stockholm Trial. Transek report.

Eliasson, J., \& Mattsson, L.-G. (2006). Equity effects of congestion pricing: Quantitative methodology and a case study for Stockholm. Transportation Research Part A: Policy and Practice, 40(7), 602620 .

Eliasson, J., Pyddoke, R., \& Swärdh, J.-E. (2016). Distributional effects of taxes on car fuel, use, ownership and purchases ( No. 2016:X). CTS Working Paper. Centre for Transport Studies, KTH Royal Institute of Technology.

Gaunt, M., Rye, T., \& Allen, S. (2007). Public Acceptability of Road User Charging: The Case of Edinburgh and the 2005 Referendum. Transport Reviews, 27(1), 85-102.

Greene, W. H. (2003). Econometric analysis. Prentice Hall.

Hamilton, C. J., Eliasson, J., Brundell-Freij, K., Raux, C., \& Souche, S. (2014). Determinants of congestion pricing acceptability ( No. 2014:11). CTS Working Paper. Centre for Transport Studies, KTH Royal Institute of Technology.

Hårsman, B., \& Quigley, J. M. (2010). Political and public acceptability of congestion pricing: Ideology and self-interest. Journal of Policy Analysis and Management, 29(4), 854-874. 
Jaensirisak, S., May, A. D., \& Wardman, M. (2003). Acceptability of Road User Charging: The Influence of Selfish and Social Perspectives. J. Schade and B. Schlag (eds.): Acceptability of Transport Pricing Strategies. Elsevier, Oxford.

Karlström, A., \& Franklin, J. P. (2009). Behavioral adjustments and equity effects of congestion pricing: Analysis of morning commutes during the Stockholm Trial. Transportation Research Part A: Policy and Practice, 43(3), 283-296.

Le Vine, S., Jones, P., \& Polak, J. (2013). The Contribution of Benefit-in-Kind Taxation Policy in Britain to the "Peak Car" Phenomenon. Transport Reviews, 33(5), 526-547.

Levinson, D. (2010). Equity Effects of Road Pricing: A Review. Transport Reviews, 30(1), 33-57.

Metcalf, G. E. (1996). The lifetime incidence of state and local taxes: measuring changes during the 1980s. In J. Slemrod (Ed.), Tax progressivity and income inequality. Cambridge University Press.

Nyborg, K. (2000). Homo Economicus and Homo Politicus: interpretation and aggregation of environmental values. Journal of Economic Behavior \& Organization, 42(3), 305-322.

Sagoff, M. (1988). The economy of the earth. Cambridge: Cambridge University Press.

Schade, J., \& Schlag, B. (2003). Acceptability of road user charging: meeting the challenge. Acceptability of transport pricing strategies, 27.

Small, K. A. (1992). Using the revenues from congestion pricing. Transportation, 19, 359-381.

Suits, D. B. (1977). Measurement of Tax Progressivity. The American Economic Review, 67(4), 747752.

West, S. E. (2004). Distributional effects of alternative vehicle pollution control policies. Journal of Public Economics, 88(3-4), 735-757. 


\section{Appendix: Estimation Results}

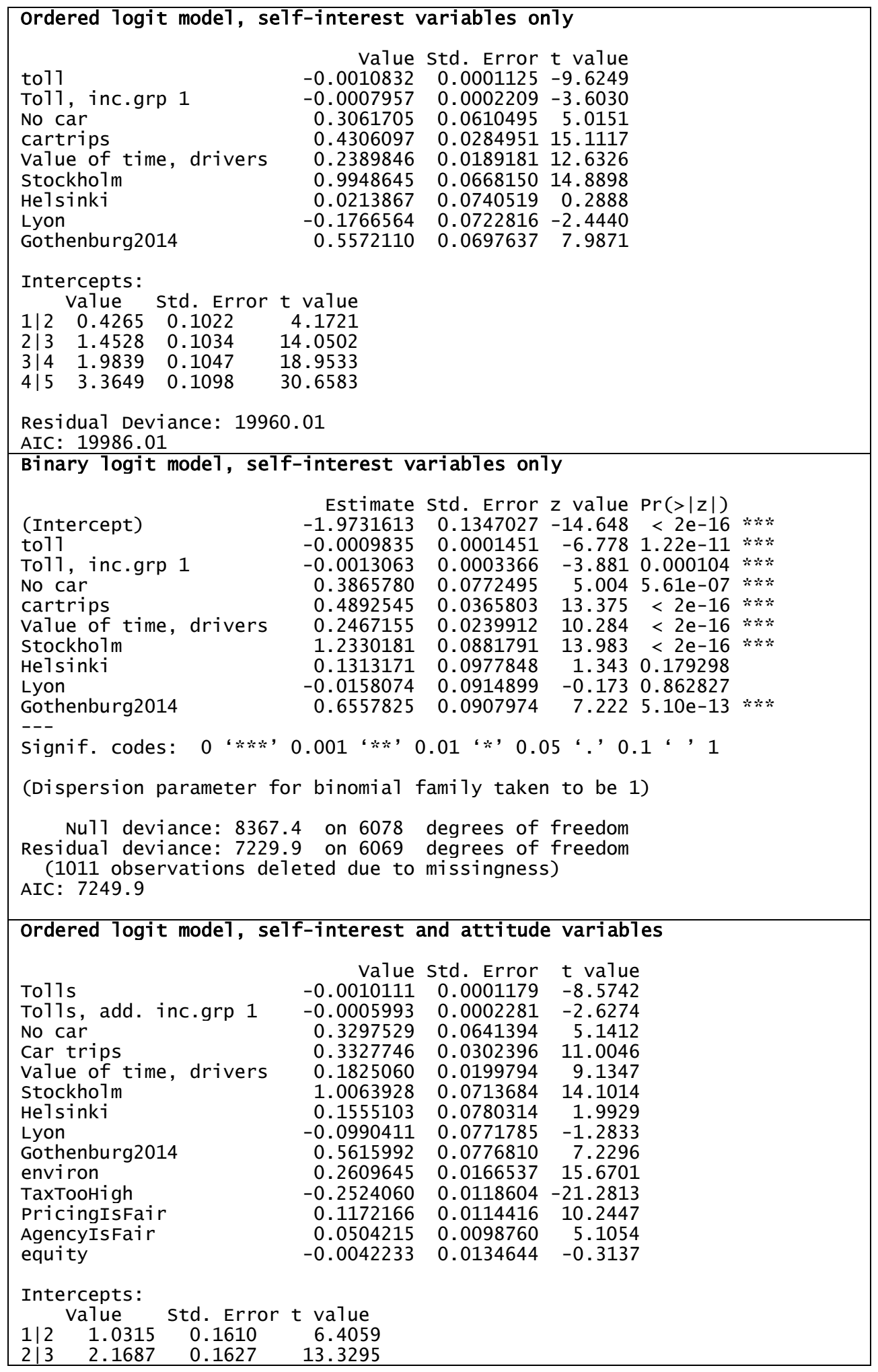




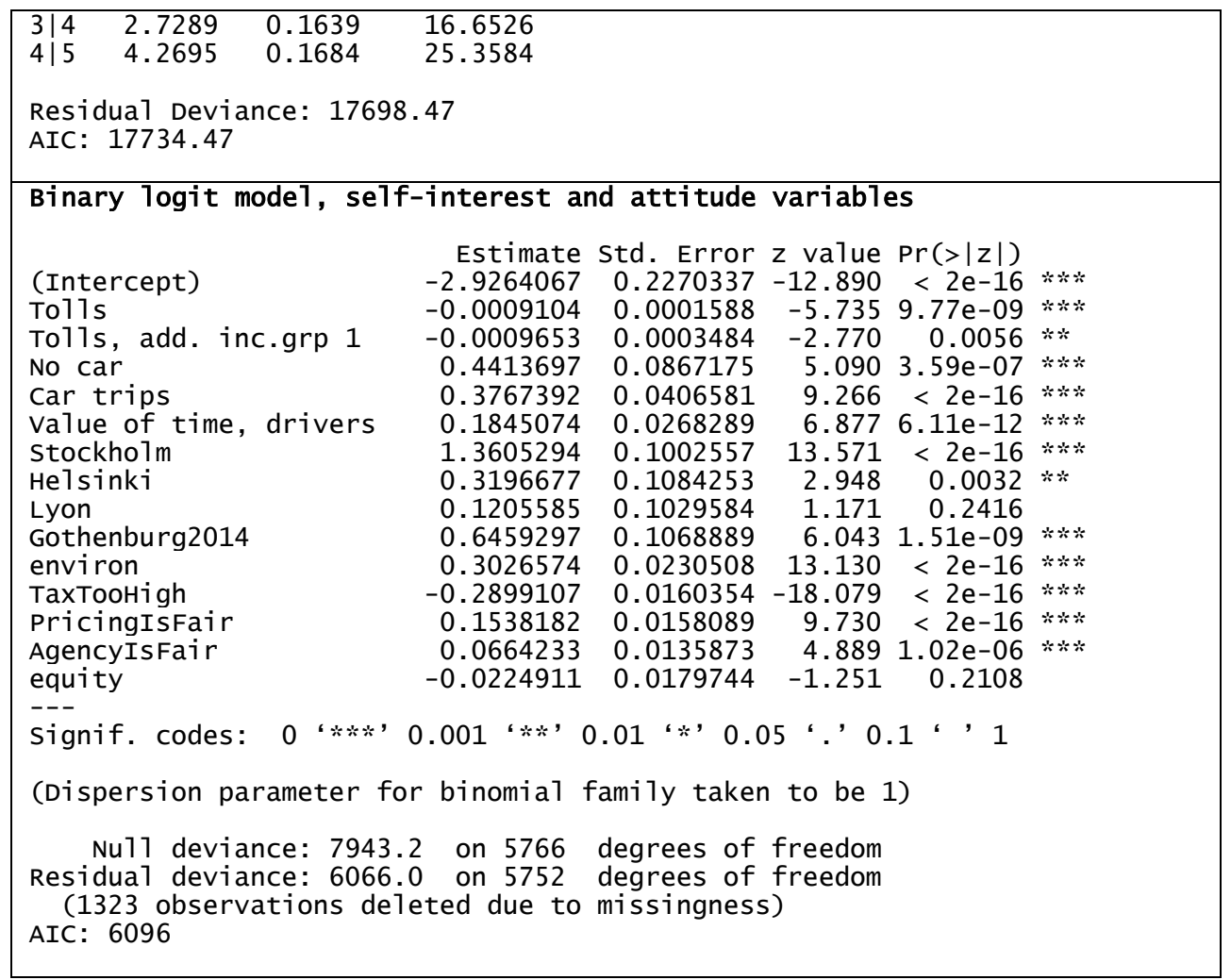


